Canadian Journal of Fisheries and Aquatic Sciences

Canadian Science Publishing

Journal canadien des sciences halieutiques et aquatiques

\title{
A state-space stock assessment model for northern cod, including under-reported catches and variable natural mortality rates
}

\begin{tabular}{|r|l|}
\hline Journal: & Canadian Journal of Fisheries and Aquatic Sciences \\
\hline Manuscript ID & cjfas-2015-0047.R1 \\
\hline Manuscript Type: & Article \\
\hline Date Submitted by the Author: & 11 -May-2015 \\
\hline Complete List of Authors: & Cadigan, Noel; Memorial University of Newfoundland, Marine Institute \\
\hline Keyword: & $\begin{array}{l}\text { STOCK ASSESSMENT < General, GADOID SPECIES < Organisms, MARINE } \\
\text { < Environment/Habitat, COMMERCIAL FISHERIES < General }\end{array}$ \\
\hline \multicolumn{2}{|c}{} \\
\hline
\end{tabular}


1 A state-space stock assessment model for northern cod, including under-reported catches and 2 variable natural mortality rates.

3

4 Noel G. Cadigan

5

6 Centre for Fisheries Ecosystems Research

7 Marine Institute of Memorial University of Newfoundland

8 P.O. Box 4920

9 St. John's, NL

10 Canada A1C 5R3

11 tel:1 709778 0603; fax: 1709778 0669; email: noel.cadigan@mi.mun.ca

12 


\section{Abstract}

14 A state-space assessment model for the northern cod (Gadus morhua) stock off southern

15 Labrador and eastern Newfoundland is developed here. The model utilizes information from

16 offshore trawl surveys, inshore acoustic surveys, fishery catch age-compositions, partial fishery

17 landings, and tagging. This is done using an approach that avoids the use of subjective data-

18 weighting. Estimates of fishing mortality rates (F) are usually conditional on assumptions about

19 natural mortality rates (M) in stock assessment models. However, by integrating much of the

20 information on northern cod it is possible to estimate $\mathrm{F}$ and $\mathrm{M}$ separately. It is also possible to

21 estimate a change in the offshore survey catchability by including inshore acoustic biomass

22 estimates. The proposed model also accounts for biased total catch statistics which is common

23 problem in stock assessments. The main goal of the model is to provide realistic projections of

24 the impacts of various levels of future fishery catches on the recovery of this stock. The

25 projections incorporate uncertainty about $\mathrm{M}$ and catch. This is vital information for successful

26 future fisheries. The model has been developed for the specific data sources available for

27 northern cod but it could be adapted to other stocks with similar data sources.

29 Keywords: censored likelihood, compositional data, integrated likelihood, tagging data, acoustic

30 surveys, process error.

32 Introduction

33 A challenge for fisheries management of the cod (Gadus morhua) stock off southern Labrador

34 and eastern Newfoundland in Northwest Atlantic Fisheries Organization (NAFO) Divisions 2J 
and 3KL (i.e. northern cod) is the lack of a stock assessment model that can be used to evaluate

36 the impacts of future fishing. There are several reasons for this. The size and spatial distribution

37 of the stock has varied greatly over the past few decades (e.g. Lilly 2008). A moratorium on

38 commercial fishing was declared in 1992 and the stock is presently still at a low level relative to

39 the 1980's. Fisheries were re-opened in the inshore in 2006 and continued during 2007-14. These

40 fisheries are difficult to monitor because there are many participants and many landings sites.

41 For example, 4306 commercial groundfish licenses were issued by Fisheries and Oceans Canada

42 (DFO) for Newfoundland and Labrador in 2010. An estimated 60352 people participated in the

43 recreational fishery in 2007 (DFO 2007). However, there are no direct estimates of recreational

44 landings for 2009-2012 and estimates in other years are considered to be uncertain (DFO 2013).

45 In addition, commercial fishers often report that recent landings for northern cod are underestimated (DFO, 2011a). This was also considered to be a problem historically for this

47 stock (e.g. Hutchings and Myers 1995; Halliday and Pinhorn 1996; Rose 2007), although the magnitude of the bias has not been quantified. Information on these fishery catches have been considered too unreliable to include in stock assessment models. Another problem is the level of natural mortality rate $(M)$. This may have increased substantially around the time of the moratorium in 1992 although the level and duration is uncertain (Lilly 2008).

Standard assessment models for northern cod fit survey data very poorly (e.g. Shelton and Lilly 2000). A survey-based model was used during 2011-13 (Cadigan 2013a). However, this model cannot be used directly to provide projections for catch advice without additional assumptions about natural mortality rates. It also does not utilize age-sampling information from commercial

56 and recreational fisheries which may be reliable even if reported landings are not. In this paper

57 the "censored-catch" approach of Hammond and Trenkel (2005) and Bousquet et. al. (2010) is 
extended to account for under-reported catches. A censored observation is one for which the

59 exact value is unknown but about which there is partial information such as a lower bound (right

60 censoring) or an interval known to cover the exact value (interval censoring). Age-composition

61 estimates from commercial and recreational fisheries are considered to be uncertain but not

62 biased. The model is extended into a state-space framework by including process errors in the

63 population dynamics model. State-space models have become the favored approach in modeling

64 time varying ecological phenomena such as population dynamics (e.g. Schnute 1994;

65 Gudmundsson 1994; Aanes 2007; Maunder and Deriso 2011; Nielsen and Berg 2014), animal

66 movement (Patterson et al. 2008) and animal behavior (Morales et al. 2004). We include

67 uncertainty about $M$ in the process error component of the model. Extensive northern cod

68 tagging information (see Brattey and Healey 2003, 2007; Brattey and Cadigan 2003; Myers et al.

69 1996) is included in the model to provide information about both fishing mortality rates $(F)$ and

$70 M$. The model we propose has been developed for the specific data sources available for northern

71 cod but it could be adapted to other stocks with similar data sources.

\section{Materials and Methods}

73 Model notation and parameters are described in the text and also Table 1.

74 The state-space model for northern cod is based on a common cohort model in which the

75 abundance at age $a$ in year $y\left(\right.$ i.e. $\left.N_{a, y}\right)$ is equal to that cohort abundance in the previous year

76 times the survival rate, which is expressed in terms of the total mortality rate $(Z)$,

$$
N_{a, y}=N_{a-1, y-1} \exp \left(-Z_{a-1, y-1}\right)
$$


77 The numbers at age in the first year are treated as unknown and free parameters to estimate. The

78 recruitments and $Z$ s are estimated as random effects, which is described later. In the northern cod 79 application $a=2, \ldots, 12$ and $y=1983, \ldots, 2012$; however, for convenience we will usually refer to 80 model ages $a=1, \ldots, A$ and years $y=1, \ldots, Y$. For example, model age 1 corresponds to stock age

812 , etc. The rationale for the selection of ages and years to model is described at the end of this

82 section. The total mortality rate is $Z_{a, y}=F_{a, y}+M_{a, y}$, where $F_{a, y}>0$ and $M_{a, y}>0$ and are unknown quantities to estimate. The Baranov catch equation is used to model catch as a function of $N, F$ and $Z$,

$$
C_{a, y}=N_{a, y}\left\{1-\exp \left(-Z_{a, y}\right)\right\} F_{a, y} / Z_{a, y}
$$

85 State-space models usually involve observations equations and errors for data used to estimate model parameters. They also have process error components to account for the approximations that most models involve. Including process error is typical of contemporary stock assessment models (Maunder and Piner 2014). Both Gudmundsson and Gunnlaugsson (2012) and Nielsen and Berg (2014) assumed multiplicative lognormal process errors $(\delta)$ in the state Equation (1); that is, $\log \left(N_{a, y}\right)=\log \left(N_{a-1, y-1}\right)-F_{a-1, y-1}-M_{a-1, y-1}+\delta_{a, y}$. In this equation, full knowledge of $F$ and $M$ does not provide full knowledge of cohort survival from one year to the next which is consistent with interpreting $\mathrm{Z}$ as an individual death rate rather than a demographic factor. Brinch et al. (2011) used somewhat different models than Equations (1) and (2) but also included process error in their cohort model equation. Gudmundsson and Gunnlaugsson (2012) suggested that the $\delta$ 's be interpreted as "irregular natural mortality", which we interpret as deviations from assumed values for $M^{\prime}$ 's. They also suggested that $\delta$ 's could represent migrations. In our state-space model we include only process error in $M$ and additional considerations are given in the Discussion. 
We model the $M$ 's as auto-correlated random variables,

$$
\log \left(M_{a, y}\right)=\log \left(m_{a}\right)+\delta_{a, y}
$$

100 A similar approach has been used for cod in the southern Gulf of St. Lawrence (Swain, 2011) 101 and discussed in Millar and Meyer (2000). The $m_{a} \mathrm{~s}$ are fixed at 0.5 for $a=1$ (i.e. stock age 2), $102 m_{a}=0.3$ for $a=2$, and $m_{a}=0.2$ for $a>2$. These values were chosen to be broadly consistent 103 with previous information about age patterns in $M$ for northern cod. We did not include annual 104 changes in $M$ in $m_{a}$; we prefer to model annual variations via $\delta$ so that this source of variability 105 can also be included in stock projections. This is considered further in the Discussion. The $M$ 106 process errors $\left(\delta_{a, y}\right.$ 's) are assumed to have a normal distribution with zero mean but autocorrelated over ages and years because $M$ 's should be more similar for fish that are close together

108 in age and time. These errors are assumed to have a stationary distribution derived from a lag 1

109 autoregressive process in both age and year so that

$$
\operatorname{Cov}\left(\delta_{a, y}, \delta_{a-j, y-k}\right)=\frac{\sigma_{\delta}^{2} \varphi_{\delta, a g e}^{j} \varphi_{\delta, y r}^{k}}{\left(1-\varphi_{\delta, a g e}^{2}\right)\left(1-\varphi_{\delta, y r}^{2}\right)}, \operatorname{Corr}\left(\delta_{a, y}, \delta_{a-j, y-k}\right)=\varphi_{\delta, a g e}^{j} \varphi_{\delta, y r}^{k}
$$

110 This is a simple choice for a covariance model that can account for the types of dependencies in

111 processes errors that one might expect. Note that age and $y r$ in Equation (4) distinguish

112 autocorrelation in the age and year dimension. They do not index age and year; we use $a$ and $y$

113 for this purpose. Additional details on this age $\times$ year time-series process are provided in the

114 Appendix. There is likely high correlation in the $M$ process errors at older ages. To simplify the 115 model the $\delta_{a, y}$ 's were coupled at stock ages $8+$; that is, each year $\delta_{8, y}=\ldots=\delta_{12, y}$. This

116 assumption also helps identify the $\sigma_{\delta}^{2}$ parameter from other variance parameters for $F \mathrm{~s}$ and data

117 sources because it removes a source of variation (i.e. change in M) at these older ages. The 
118 process errors in the first year are also partially confounded with the initial abundance

119 parameters which are freely estimated. We constrained these errors to all equal zero. Swain

120 (2011) did the same thing in his $M$ random walk model.

121 Fishing mortalities are modelled similar to the $M$ process errors, with

$$
\operatorname{Cov}\left\{\log \left(F_{a, y}\right), \log \left(F_{a-j, y-k}\right)\right\}=\frac{\sigma_{F}^{2} \varphi_{F, a g e}^{j} \varphi_{F, y r}^{k}}{\left(1-\varphi_{F, a g e}^{2}\right)\left(1-\varphi_{F, y r}^{2}\right)} .
$$

122 We fixed $\varphi_{F, y r}=0.9$ to make the process more similar to a random walk, consistent with the 123 recommendation of Maunder and Piner (2014). Gudmundsson and Gunnlaugsson (2012) and

124 Nielsen and Berg (2014) also included correlated random walk processes for $F$ s. The within-year 125 correlation of $F^{\prime} \mathrm{s}, \varphi_{\delta \text {, age }}$, was estimated for stock ages 5-12 but it was fixed at zero for ages 2-4.

126 Northern cod at these ages are small, generally weighing much less than $0.5 \mathrm{~kg}$ (see Table 2 in 127 Cadigan 2013b), and these fish are not targeted by commercial fisheries, while age $5(\sim 1 \mathrm{~kg})$ is 128 often considered to be a targeted size. Hence, we do not expect the same correlation between $F$ at 129 ages 2-4 compared to 5+. No likelihood function was used for $F_{1-3,1}$ (model ages) similar to 130 Nielsen and Berg (2014), although we did specify a likelihood function for $F_{4-11,1}$ to account for 131 autocorrelation at these ages which is different from Nielsen and Berg (2014). The $F$ model 132 component explicitly involves just two parameters: $\sigma_{F}^{2}$, and $\varphi_{\delta \text {, age }}$, but $F_{1-3,1}$ are also like free 133 parameters.

134 The recruitments, $N_{1,1}, \ldots N_{1, Y}$, are also treated as uncorrelated lognormal random variables,

$$
\log \left(N_{1, y}\right) \sim N\left(r_{p}, \sigma_{r}^{2}\right), r_{p}=\left\{\begin{array}{l}
r_{1}, y \leq 1992 \\
r_{2}, y>1992
\end{array}\right.
$$


135 The two mean recruitment parameters $\left(r_{1}, r_{2}\right)$ were chosen to reflect the large differences in 136 stock size before and after 1992 (e.g. Lilly 2008). The variance, $\sigma_{r}^{2}$, was fixed at 1.0 which is a

137 large value; hence, the $\mathrm{N}_{1, \mathrm{y}} \mathrm{s}$ are almost freely predicted except for the very recent recruitments 138 that have little data to inform estimation. However, we assess the impact of alternative choices 139 for $\sigma_{r}^{2}$.

140 Model likelihood equations

\section{Catch}

142 Little information has been published by DFO on the methodologies they use to estimate catch 143 and the precision of their estimates has not been quantified. However, as noted in the

144 Introduction there are reasons to suspect that there has been under-reporting of commercial

145 landings and that recreational catches are difficult to estimate reliably. DFO nominally assumes

146 these statistics are census values with some error. We assume the catch measurement process

147 involves some error (i.e. not a perfect census) and that not all catches are included so that the 148 DFO catch statistics provide a stochastic lower bound on true catches, depending on the

149 magnitude of measurement error $\left(\sigma_{C}^{2}\right)$. Similar to Bousquet et al. (2010) we also assume there is

150 an upper bound on true catches that is some multiple of reported catches. We set the upper bound

151 to $2 \times$ reported catch at ages 2-12 (e.g. Hammond and Trenkel 2005) for 1993-2012 but 1.5x

152 during 1983-1992 when reported catches were much higher and the fraction of unreported catch

153 may be lower. This is based on the assumption that the amount of cod that could be marketed

154 and sold illegally is roughly fixed over time and probably a much lower fraction of reported

155 catches prior to 1992 compared to since then. However, discarding of fish at sea and on land may 
156 have been higher before 1992. The choice of upper bounds is subjective and we examine the 157 sensitivity of the model to a different choice for the upper bounds.

158 Let $C_{y}$ denote the total model predicted catch obtained by summing Equation (2) over stock ages

159 2-12. Let $C_{o y}$ denote the observed catch and let $U_{y}$ denote the upper bound on catches. The 160 measurement error is assumed to be lognormal and the censored log-likelihood for the observed 161 catch time series is

$$
l\left(C_{o 1}, \ldots, C_{o Y} \mid \theta\right)=\sum_{y=1}^{Y} \log \left[\Phi_{N}\left\{\frac{\log \left(U_{Y} / C_{Y}\right)}{\sigma_{C}}\right\}-\Phi_{N}\left\{\frac{\log \left(C_{o Y} / C_{Y}\right)}{\sigma_{C}}\right\}\right]
$$

162 where $\Phi_{N}$ is the cumulative distribution function (CDF) for a $N(0,1)$ random variable. We have 163 no information to estimate $\sigma_{C}$. We simply fix it at a small value, $\sigma_{C}=0.01$, to make sure that $C_{y} \in$ $164\left(C_{o y}, U_{y}\right)$ for most years and can otherwise exceed the bounds only by a small amount. In this 165 case the likelihood has a value of one inside the bounds, and zero outside, with a smooth 166 transition between one and zero near the bounds. The log-likelihood can be very small even for 167 values of $C_{Y}$ that are slightly outside of the bounds and this can lead to problems when 168 optimizing the likelihood. The solution we use is the replace $\Phi_{N}\left(\cdot / \sigma_{C}\right)$ in Equation (7) with a 169 mixture of normals, $\Phi_{N}^{*}\left(\cdot / \sigma_{C}\right)=p \Phi_{N}\left(\cdot / \sigma_{C}\right)+(1-p) \Phi_{N}\left(\cdot / \sigma_{C}^{*}\right)$, with $p=0.9$ and $\sigma_{C}^{*}=0.075$.

170 Optimizing the total likelihood including Equation (7) is sensitive to starting values for

171 parameters even when the normal mixture distribution is used. If model predicted catches are 172 significantly low (i.e. $C_{y}<0.7 \times C_{o y}$ ) or high (i.e. $C_{y}>1.3 \times U_{y}$ ) then Eqution (7) becomes the $173 \log$ of a very small number and creates a flat ridge on the likelihood surface. This seems to cause 174 the parameter estimation procedure we use to diverge. The procedure we used to get better 175 starting values is to first fit the model assuming total catches were $\left(C_{o y}+U_{y}\right) / 2$ with 176 measurement error $\sigma_{C}$. This ensures that model predicted catches at starting values are in the 9 
177 interval $\left(C_{o y}, U_{y}\right)$. Then we fit the model using Equation (7), and convergence is usually not a 178 problem (see Simulations).

179 The age distribution of the catches provides important information on mortality rates. Annual 180 sampling of the commercial catch for ages, lengths and weights has been used by DFO to 181 estimate the commercial catch at age. The sampling protocols are complex and have changed 182 over time. Periodic publications by DFO describe some of this, but the most recent publication is 183 DFO (2011). It is practically impossible to evaluate from first principles the statistical properties 184 of the catch age composition information (i.e. catch proportions at age) for northern cod, 185 although this is an active area of research in general (e.g. Thorson 2014). There have been 186 numerous publications focusing on how to model age and length composition information. 187 Recently Francis (2014) reviewed much of this literature and also studied some of the common 188 approaches using many data sets and simulation analyses. He also studied the logistic normal 189 multinomial distribution, which is commonly advocated for analyses of compositional data 190 (Aitchison 2003), but not commonly used in stock assessment (except Schnute and Haigh 2007; 191 Martell 2011; Martell et al. 2011).

192 We use a related approach (see Appendix) based on the continuation-ratio logit which has been 193 used for modelling length and age distributions (e.g. Kvist et al. 2000; Rindorf and Lewy 2001; 194 Berg and Kristensen 2012). Let $X_{a, y}$ be the continuation-ratio logit (Equation A.4 in Appendix) 195 of $P_{a, y}=C_{a, y} / C_{y}$ derived from Equation (2). Let $X_{o a, y}$ denote the observed continuation-ratio logit 196 based on the data with zero's replaced (see Appendix). The catch age composition log-likelihood 197 is 


$$
l\left(\left\{X_{o a, y}\right\} \mid \theta\right)=\sum_{a=1}^{A-1} \sum_{y=1}^{Y} \log \left\{\varphi_{N}\left(\frac{X_{o a, y}-X_{a, y}}{\sigma_{P a}}\right)\right\}
$$

where $\varphi_{N}$ is the probability distribution function (pdf) for a $N(0,1)$ random variable,

$$
\sigma_{P a}=\left\{\begin{array}{cc}
3 \sigma_{P}, & a \leq 2 \\
\sigma_{P}, & 3 \leq a \leq 7 \\
2 \sigma_{P}, & a \geq 8
\end{array}\right.
$$

and $\sigma_{P}$ is an estimated parameter. The ad hoc age adjustments to $\sigma_{P}$ were chosen with a few iterations to account for additional residual variability at these ages. We recommend that standardized residuals be carefully inspected for appropriate residual variation. The errors in $P_{a, y}$ 's are assumed to be independent but including correlation, particularly across ages, is possible.

\section{Surveys}

Surveys provide important information for estimating model parameters. Let $I_{s, a, y}$ denote the agebased abundance index for survey $s$. The main index used for assessing northern cod comes from the DFO offshore research vessel (RV) survey. The inshore gillnet catch-rate index provided by the Sentinel fishery program is also used. Let $t$ be the midpoint of the survey dates which is expressed in a fraction of the year. The model predicted catch for survey $s$ is

$$
E\left(I_{s, a, y}\right)=\mathrm{q}_{s, a} \mathrm{~N}_{a, y} \exp \left(-\mathrm{t}_{s, y} \mathrm{Z}_{a, y}\right)
$$

The $\exp \left(-t_{s, y} Z_{a, y}\right)$ term projects beginning-of-year stock abundance $\left(N_{a, y}\right)$ to the time of the survey. The $q_{s, a}$ 's are catchability parameters that adjust stock abundance to the scale of the surveys. If the survey indices are estimated totals for the entire survey area, as is the case in this application for the DFO RV survey, then the qs may be close to one. DFO survey indices for 
214 ages 2-12 and years 1983-2012 are used for model estimation. Indices for age one are not used

215 because at this age a substantial amount of cod may be outside of the survey area and the

216 catchability at this age will be highly variable. Very few cod are caught at ages older than 12

217 throughout the RV survey time-series. Ages 3-10 for 1995-2012 are used for the Sentinel gillnet

218 series, which started in 1995 . The gear used in this program catches very few fish outside of this

219 range of ages.

220 The indices are assumed to have a lognormal distribution with mean $E\left\{\log \left(I_{a, y}\right)\right\}=\log \left(q_{a}\right)+$

$221 \log \left(N_{a . y}\right)-t_{y} Z_{a . y}$ and standard deviation $\sigma_{I}$ which is also an estimated parameter. The indices

222 at all ages in 1986 were anomalously high although the reasons for this are poorly understood

223 (e.g. Baird et al 1991). This was also evident for other groundfish species caught in that year. To

224 accommodate the apparent extra survey error in $1986, \sigma_{I}$ was fixed to be 0.5 for that year. The

225 likelihood term for survey indices is

$$
l\left(\left\{I_{s, a, y}\right\} \mid \theta\right)=\sum_{a} \sum_{y} \log \left(\varphi_{N}\left[\frac{\log \left(I_{a, y}\right)-E\left\{\log \left(I_{a, y}\right)\right\}}{\sigma_{I}}\right]\right) .
$$

226 The lognormal distribution requires survey indices to be positive (i.e. no zero's). However, 19\%

227 of the DFO RV indices had zero values, mostly at older ages. In many stock assessment models

228 these zeroes are treated as missing values but this does not seem appropriate in our case. We

229 assume these indices were zero because of low stock abundance in the survey area and not

230 because the fish were missed by mistake. We assume that these zero's represent stock densities

231 that are below a detection limit which we set at 0.005 which is half of the minimum positive

232 value in the data series. The log-likelihood for a zero index is

$l\left(I_{s, a, y}=0 \mid \theta\right)=\log \left(\Phi_{N}\left[\log \left\{0.005 / E\left(I_{a, y}\right)\right\} / 4 \sigma_{I}\right]\right)$, where $\Phi_{N}$ is the Normal CDF and the 
234 standard deviation is increased by four to account for additional variability. The log-likelihood

235 for a zero will be close to zero if $E\left(I_{a, y}\right) \ll 0.005$ which is very different from substituting 0.005

236 for a zero index and using Equation (10) for its distribution.

237 The model is highly parameterized and includes a modelling component for $M$. The age patterns 238 in $q$ s are usually confounded with the level of $Z=F+M$ and it is helpful to fix the age patterns 239 at reasonable values if possible. Most of the northern cod stock over-wintered in the offshore in 240 the 1980's (e.g. Lilly 2008) and much of it would have been available to the DFO autumn RV 241 survey. During this period we have no data or good reasons to expect that $q$ at older ages

242 deviated from a constant value. Therefore, we constrained DFO RV qs to be the same values for 243 stock ages 5-12 and lower at ages 2-4. In most preliminary analyses the values did not differ for 244 ages 3-12 (i.e. models ages 2-11) and so we further simplified the RV q's,

$$
q_{a}=\left\{\begin{array}{cc}
\rho_{a} q_{\text {full }}, & a=1, \\
q_{\text {full }}, & a>1,
\end{array}\right.
$$

245 where $\rho_{a}<1$. However, we explore the sensitivity of this assumption using a model formulation

246 in which $q$ 's are estimated freely for most ages. The Sentinel gillnet index has a dome-shaped

247 age pattern in $q$ so we simply estimated these parameters freely for each age.

\section{Spatial model for DFO RV q}

249 A fundamental assumption in Equation (9) is that $q$ is constant over time for each age class in the 250 population. However, after the stock collapsed in the early 1990's it is very plausible that $q$ 251 changed for the DFO RV survey. Not all northern cod are in the area surveyed each fall. This 252 may be more so for younger cod that have grown in inshore areas and become more migratory as 253 they get older. A relatively large inshore aggregation of cod was first observed in the spring of 
2541995 in Smith Sound, Trinity Bay, on the northeast coast of Newfoundland. (e.g. Rose et al.

255 2011). Their acoustic biomass estimates of this over-wintering stock component ranged from

256 about 10000 to 25000 tonnes but declined substantially in 2008 and 2009 to a much lower level

257 of less than 1000 tonnes, and has been about this level since then (G. Rose, Marine Institute of

258 Memorial University of Newfoundland, St. John's, NL, personal communication, 2014). Rose et

259 al. (2011) concluded that these fish were immigrants from an offshore stock component but it is

260 not clear if their rapid disappearance from Smith Sound starting around 2008 was a reverse

261 migration back to the offshore over-wintering area or movement to other inshore over-wintering

262 areas. However, the DFO RV survey index of spawning stock biomass (SSB) in the offshore

263 increased by $83 \%$ during 2004 to 2008 (Brattey et al. 2010), while there have been no

264 observations of large over-wintering inshore components since 2009. Rose et al. (2011)

265 concluded that $F$ and $M$ were unlikely to explain the full decline of the Smith Sound component

266 during 2008-2009. Hence, we conclude that reverse migration is a highly plausible scenario to

267 include in our stock assessment model. This potential change in the spatial distribution of the

268 stock could explain some of the high levels of total mortality rates inferred from the DFO RV

269 survey during this time-period.

270 Offshore stock components in this scenario are assumed to migrate inshore and mix with inshore

271 components to feed in the summer. All components are assumed to be equally exploited by the

272 inshore fishery including the Sentinel fishery program. We also assume that both $M$ and $Z$ are the

273 same for the inshore and offshore components. We assume that a portion of the offshore stock

274 was not available to the DFO survey during 1995-2009, in addition to those inshore components

275 that are never available to this survey and are accounted for in the stock assessment model by the

$276 q_{a}$ parameters in Equation (9); that is, 


$$
E\left(I_{R V, a, y}\right)= \begin{cases}\mathrm{q}_{a} \mathrm{~N}_{a, y} \exp \left(-\mathrm{tZ}_{a, y}\right), & y \neq 1995, \ldots, 2009 \\ \mathrm{q}_{a}\left(\mathrm{~N}_{a, y}-\mathrm{N}_{S a, y}\right) \exp \left(-\mathrm{tZ}_{a, y}\right), & y=1995, \ldots, 2009\end{cases}
$$

277 where $N_{S a, y}$ is the abundance of offshore fish that migrated and over-wintered in Smith Sound.

278 The estimation procedure we use for $N_{S a, y}$ is described at the end of this section. Equation (9) is 279 used for the Sentinel indices but with different $q$ 's and $t=0.5$.

280 The size of the Smith Sound component is estimated using acoustic biomass estimates $\left(\widehat{B}_{S y}\right)$ in

281 Rose et al. (2011), with the observation equation

$$
\log \left(\widehat{B}_{S, y}\right) \sim N\left\{\log \left(\sum_{a=1}^{A} \mathrm{q}_{S, a} \mathrm{~N}_{S, a, y} \exp \left(-\mathrm{t}_{y} \mathrm{z}_{a, y}\right) \mathrm{w}_{a, y}\right), \hat{\sigma}_{S y}^{2}\right\},
$$

where $q_{S, a}$ are catchability parameters for the acoustic survey with $\max _{a} \mathrm{q}_{S, a}=1, w_{a, y}$ are stock weights at age, and $\hat{\sigma}_{S, y}$ is the estimated $\mathrm{CV}$ of the biomass estimate provided for each survey. Beginning of year stock size is projected to the time of the acoustic surveys which have usually been in January but in a few years were April-June. Age composition information was also provided in Rose et al. (2011) and we use this to estimate the age composition of cod in Smith Sound; however, to do this we fix the $q_{S, a}$ parameters because they cannot be reliably estimated with the data we use. During the surveys there seemed to be very few small cod (or any other fish species) in Smith Sound, possibly due to predation by the larger cod. Therefore, we assume that $q_{S, 1}=0.7, q_{S, 2}=0.9$ and $q_{S, 3+}=1$ (i.e. stock ages $4+$ ).

The Smith Sound age information was based on simple trawl samples in which the age was determined for all cod caught. The Negative Binomial (NB) distribution is often considered to be appropriate for modelling the variability in trawl catches (e.g. Cadigan 2011). We assumed the age sample catches $\left(J_{S, a, y}\right)$ were 


$$
J_{S, a, y} \sim N B\left\{\mathrm{q}_{s, y} \mathrm{q}_{s, a} \mathrm{~N}_{S, a, y}, k\right\}
$$

where $q_{S, y}$ is the fully selected exploitation rate for the age samples collected in year $y$. This extremely small exploitation rate is estimated each year. If we denote the mean of $J_{S, a, y}$ as $\mu_{S, a, y}=\mathrm{q}_{S, y} \mathrm{q}_{S, a} \mathrm{~N}_{S, a, y}$ then for the NB distribution $\operatorname{Var}\left(J_{S, a, y}\right)=\mu_{S, a, y}+\mu_{S, a, y}^{2} / k$ and $k$ is an over-dispersion parameter to estimate.

We prefer to model the Smith Sound inshore stock distribution during 1995-2009 using $D_{a, y}=$ $N_{S a, y} / N_{a, y}$ so that $N_{S, a, y}=D_{a, y} N_{a, y}$ and $N_{a, y}-N_{S, a, y}=\left(1-D_{a, y}\right) N_{a, y}$ in Equations (12) - (14). We expect these $D$ proportions to vary smoothly over time and with age. We model this behavior using an age and year $\mathrm{AR}(1)$ process for the logit of $D$, with parameters $\sigma_{D}^{2}, \varphi_{D, \text { age }}$ and $\varphi_{D, y r}$ (see Table 1). Hence, $D$ is an age and year dependent modification of the DFO RV $q$ model (Equation 12),

$$
E\left(I_{R V, a, y}\right)= \begin{cases}\mathrm{q}_{a} \mathrm{~N}_{a, y} \exp \left(-\mathrm{tZ}_{a, y}\right), & y \neq 1995, \ldots, 2009 \\ \mathrm{q}_{a}\left(1-\mathrm{D}_{a, y}\right) \mathrm{N}_{a, y} \exp \left(-\mathrm{tZ}_{a, y}\right), & y=1995, \ldots, 2009\end{cases}
$$

\section{Tagging data}

We used two published sources of tag recaptures. The first was Brattey and Healey (2007) who presented release and recapture information from 84 tagging experiments conducted in Divisions 3KL during 1997-2006. A total of 32544 fish were tagged in these experiments and 4894 were recaptured. The second source was Myers et al. (1996) who presented information for 16 experiments conducted during 1983-1987 in Division 3K. A total of 10484 fish were tagged and 2083 were recaptured. Brattey and Healey (2007) presented the average fish length at the time of release. We obtained this information for the experiments in Myers et al. (1996) from Taggart et al. (1995). These data were age-aggregated which causes some difficulties with using this 
314 information in our age-structured model. A simple approach is to assume all fish in each

315 experiment are the same age. We estimated the average age of the fish when they were tagged

316 using the average length of the releases and the fall survey average age at length information for

$3173 \mathrm{~K}$ cod in Brattey et al. (2010; Figure 39a). We can then use the $F$ for that age to model

318 recaptures. In preliminary analyses we found the model to be unstable and difficult to estimate.

319 Treating the tagging data this way limits the number of cohorts that the data provide $F$ and $M$

320 information about and this may be the reason we had problems.

321 The tagging data provide $F$ and $M$ information for an aggregation of ages. Let $N_{x, a, y}$ denote the

322 unknown number of fish tagged at age $a$ in year $y$ for some experiment $x$. We only know the total

323 number of tagged fish, $N_{x, y}=\sum_{a=1}^{A} N_{x, a, y}$. For exposition we assume fish are tagged at the

324 beginning of the year although in application we adjust for the seasonal time of tagging. Using

325 Equation (1),

$$
N_{x, y+1}=N_{x, y} \exp \left(-\tilde{Z}_{x, y}\right), \tilde{Z}_{x, y}=-\log \left\{\frac{\sum_{a=1}^{A} N_{x, a, y} \exp \left(-Z_{a, y}\right)}{N_{x, y}}\right\}
$$

326 We can decompose $\tilde{Z}_{x, y}$ into components due to fishing and natural mortality,

$$
\tilde{F}_{x, y}=-\log \left\{\frac{\sum_{a=1}^{A} N_{x, a, y} \exp \left(-F_{a, y}\right)}{N_{x, y}}\right\}, \quad \tilde{M}_{x, y}=\tilde{Z}_{x, y}-\tilde{F}_{x, y}
$$

327 However, we don't know the age composition of $N_{x, y}$ so we cannot compute $\tilde{Z}_{x, y}$ directly in the 328 model. Only cod $\geq 45 \mathrm{~cm}$ fork length (FL) were tagged (Brattey and Healey 2007) so we expect 329 that $\tilde{Z}_{x, y}$ is virtually a weighted average of $Z$ 's for ages $4-12$, but not equal weighted because the 330 average age at release could be as high as eight years old in some experiments. 
331 The procedure we used is based on the stock size-weighted versions of $\widetilde{F}_{x, y}$ and $\widetilde{M}_{x, y}$. Let $N_{+, a, y}$

332 denote the total number of fish at ages $a, a+1, \ldots, A$ for any age $a>1$. Using Equation (1),

$$
N_{+, a+1, y+1}=N_{+, a, y} \exp \left(-\tilde{Z}_{+, a, y}\right), \tilde{Z}_{+, a, y}=-\log \left\{\frac{\sum_{i=a}^{A} N_{i, y} \exp \left(-Z_{i, y}\right)}{\sum_{i=a}^{A} N_{i, y}}\right\}
$$

333 and

$$
\tilde{F}_{+, a, y}=-\log \left\{\frac{\sum_{i=a}^{A} N_{i, y} \exp \left(-F_{i, y}\right)}{\sum_{i=a}^{A} N_{i, y}}\right\}, \quad \tilde{M}_{+, a, y}=\tilde{Z}_{+, a, y}-\tilde{F}_{+, a, y} .
$$

334 Let $\tilde{F}_{x, \bar{a}, y}$ denote the $F$ for tagged fish that are average age $\bar{a}$ in year $y$. We do not use $\tilde{F}_{+, \bar{a}, y}$ to approximate $\tilde{F}_{x, \bar{a}, y}$ because $\tilde{F}_{+, \bar{a}, y}$ is for fish age $\bar{a}$ and older and could be biased for $\tilde{F}_{x, \bar{a}, y}$ which

336 includes mortality rates for some ages less than $\bar{a}$. As a solution we computed the average age of

337 the catch each year for fish older than plus group ages $4,5, \ldots, 12$ and computed $\bar{a}_{y c}$ as the

338 minimum plus group age where the corresponding average age of the catch was greater than or

339 equal to $\bar{a}$. Note that $\bar{a}_{y c} \leq \bar{a}$. We approximated $\tilde{F}_{x, \bar{a}, y}$ as $\tilde{F}_{+, \bar{a}_{y c}, y}$, although stochastically as

340 described below. Usually $\bar{a}_{y c}=\bar{a}-1$ but sometimes the difference could be two or three ages.

341 A better solution is to estimate the age-composition of the tagged fish, and then model the tag-

342 returns by experiment and age at capture; however, this information was not available for this

343 paper.

344 The size of the tagged population after release is also affected by the tag loss rate each year $\left(\gamma_{y}\right.$;

345 see Appendix). If $N_{x, \bar{a}, y}$ tagged fish from experiment $x$ survive to year $y$ and are average age $\bar{a}$,

346 then the size of the tagged population in year $y+1$ is modelled as 


$$
N_{x, \bar{a}+1, y+1}=N_{x, \bar{a}, y} \exp \left(-\tilde{F}_{x, \bar{a}, y}-\tilde{M}_{+, \bar{a}, y}-\gamma_{y}\right)
$$

347 For each experiment fish were tagged in specific geographic locations and the $F$ they

348 experienced was likely different from the stock as a whole. We assumed these differences were

349 random such that

$$
\log \left(\tilde{F}_{x, \bar{a}, y}\right) \sim N\left\{\log \left(\tilde{F}_{+, \bar{a}_{y c}, y}\right), \sigma_{f x}^{2}\right\}
$$

350 The tag catch $\left(C_{x, \bar{a}, y}\right)$ was modelled similar to Equation (2),

$$
C_{x, \bar{a}, y}=N_{x, \bar{a}, y}\left\{1-\exp \left(-\tilde{Z}_{x, \bar{a}, y}-\gamma_{y}\right)\right\} \frac{\tilde{F}_{x, \bar{a}, y}}{\tilde{Z}_{x, \bar{a}, y}+\gamma_{y}}
$$

351 In the year of release only a fraction of $F$ and $Z$ were applied, depending on the fraction of a year 352 that the tagged fish were at liberty. Initial tagging mortality was also applied, as described below.

353 For various reasons fishermen do not report all tagged fish they catch. For the recent tagging 354 experiments the reporting rates can be estimated using information from high reward tagging. 355 This has received considerable attention (Brattey and Cadigan 2003 and Cadigan and Brattey 356 2006) and recently Konrad et al. (2014) proposed a time-series approach to estimate annual 357 reporting rates (i.e. $\lambda_{y}$ ) for these experiments. For simplicity we use their estimates as fixed 358 constants (denoted as $\lambda_{\text {oy }}$ in Equation 21 below), although it is possible to add a likelihood 359 component for these parameters. We also use the estimates of short-term tagging mortality from 360 Brattey and Cadigan (2003). Myers et al. (1996) did not have information to estimate reporting 361 rates externally. They adjusted for this within their tagging model (i.e. their $\theta$ parameter) but 362 could not estimate annual reporting rates. In fact they adjusted for the combined effects of initial 363 tag loss, initial tagging mortality, and reporting rates as a single parameter that they estimated 
364 separately for each experiment. We follow the same approach, and denote this parameter as $\lambda_{x}$.

365 We estimated a total of 16 of these fixed-effect parameters for each of the 16 tagging

366 experiments in Myers et al. (1996) that we use. Hence, we use the notation $\lambda_{x, y}$ for reporting rates,

367 and the model predicted reported tag catch is

$$
R_{x, \bar{a}, y}=\lambda_{x, y} \times C_{x, \bar{a}, y}, \quad \lambda_{x, y}= \begin{cases}\lambda_{o y}, & y=1997, \ldots, 2006 \\ \lambda_{x}, & y=1983, \ldots, 1989\end{cases}
$$

368 The observed tag catches from experiment $x$ conducted in year $y_{x}$ and caught in subsequent years

$369\left(R_{o x, \bar{a}, y}\right)$ are modelled as Poisson random variables. We only used tag recaptures up to five years 370 at liberty for the Myers et al. (1996) experiments because that was all they tabulated. Recaptures

371 for up to nine years at liberty were provided by Brattey and Healey (2007). Let $T_{x}$ denote the set

372 of years that recaptures are available for experiment $x$. The likelihood term for tagging data is

$$
l\left(\left\{R_{o x, \bar{a}, y}\right\} \mid \theta\right)=\sum_{x} \sum_{t \in T_{x}} R_{o x, \bar{a}, y} \log \left(R_{x, \bar{a}, y}\right)-R_{x, \bar{a}, y}-\log \left\{\Gamma\left(R_{o x, \bar{a}, y}+1\right)\right\}
$$

\section{$373 \quad$ Random effects}

374 In addition to likelihoods for data, likelihoods for random effects like the process errors must

375 also be specified. The stochastic processes for $\log (F), \log (M)$, and $\operatorname{logit}(D)$ are auto-correlated

376 over ages and years and an efficient method for specifying these log-likelihoods is outlined in the

377 Appendix. Recall that the $M$ process errors were coupled at stock ages $8+$ and that these errors

378 were fixed at zero for the first year and a likelihood equation is not required for these fixed

379 values. The first order age auto-correlation parameter for $\log (F), \varphi_{\delta, \text { age }}$, was constrained to be

380 zero for stock ages 2-4 but estimated as a common values for other ages. No likelihood function

381 was used for $F$ at ages 1-3 in the first year. The likelihoods for both log recruitments (Equation 
382 7) and $\log F$ 's for tagging experiments (Equation 19) were based on the Normal distribution

383 likelihood with variance parameters estimated as part of the model.

\section{Estimation}

385 Fixed effects parameters, denoted collectively as the parameter vector $\theta$, are estimated via maximum likelihood (MLE) based on the marginal likelihood, $L(\theta)$, in which random effects are “integrated out". Let $\Psi$ denote a vector of all random effects. Let $S$ denote the set of all data used in the model, including surveys, catches, etc. The marginal likelihood is

$$
L(\theta)=\iiint_{\Psi} f_{\theta}(S \mid \Psi) g_{\theta}(\Psi) \partial \Psi
$$

389

where $f_{\theta}(S \mid \Psi)$ is the joint pdf of the data and $g_{\theta}(\Psi)$ is the joint pdf for the $\Psi$ random effects. The template model builder (TMB; Kristensen, 2013) package within R (R Core Team, 2014) was used to implement the model. The MLE's of $\theta$ maximize $L(\theta)$. The user has to provide C++ computer code to calculate $f_{\theta}(S \mid \Psi)$ and $g_{\theta}(\Psi)$ but the integration in Equation (23) and calculation of $\theta$ to maximize this equation is then provided by TMB. The high dimensional integral is numerically evaluated in TMB using the Laplace approximation. The random effects $\Psi$ can be predicted by maximizing the joint likelihood, $f_{\theta}(S \mid \Psi) g_{\theta}(\Psi)$; however, these effects are not freely estimated like $\theta$. If no distribution is provided for a random effect then this effect is still integrated out of the likelihood when estimating $\theta$ but the prediction of the random effect is otherwise the same as if this effect was considered to be fixed (i.e. a regular parameter). Additional information on these procedures is provided by Skaug and Fournier (2006). TMB used automatic differentiation to evaluate the gradient function of Equation (23) and in the Laplace approximation. The gradient function is produced automatically from $f_{\theta}(S \mid \Psi)$ and 
$402 g_{\theta}(\Psi)$. This greatly improves parameter estimation using a derivative-based optimizer. We use 403 the $n \operatorname{lminb}$ function within R (R Core Team 2014) to find the MLE for $\theta$.

404 The reliability of model estimates was assessed through detailed examination of model estimates 405 and residuals, and also retrospective analyses in which the model was fit to less data and results 406 compared with estimates based on the full data time-series. Models were fit to subsets of data 407 with recent years left out. This was done for retrospective years 2005 to 2011.

\section{Simulation testing}

409 Simulation testing is important especially for models with random walks (Deroba et al. 2014). A

410 full testing of the accuracy and robustness of our model, including stock size estimates and other 411 statistical inferences, is beyond the scope of this paper. However, a simple simulation self-test 412 (i.e. Deroba et al. 2014) was conducted in which the model was fit to simulated data generated 413 by the model. This does not really address the reliability of the assumptions of the model but 414 rather it simply addresses how reliable are model estimates assuming the model is correct and 415 can be viewed as a minimum test of model suitability. We conducted conditional self-test 416 simulations, by conditioning on the process errors when generating simulation data. However, 417 these process errors were not fixed when estimating the model with the simulated data. This is 418 the same simulation procedure used by Nielsen and Berg (2014).

419 The self-test simulations involved computing model predictions of the surveys (acoustic, trawl, 420 gillnet), catch age composition, and tagging data, and then randomly simulating these data using 421 the model predictions and assumed statistical distributions in the various likelihood components. 422 Data were simulated using estimated variance parameters. Simulated continuation ratio logits of 
423 the age compositions were generated using model estimates of $X_{a, y}$ and $\sigma_{P}$ (i.e. $\hat{X}_{a, y}$ and $\hat{\sigma}_{P}$ ). The 424 model was then fit to the simulated data and the procedure was repeated 1200 times.

\section{Catch projections}

426 An important way fishery science can assist fishery management is by providing reliable

427 projections of the implications of future catch levels. There is uncertainty about the exact values

428 of catches for northern cod but we can do catch projections based on the model estimates of

429 catch. We evaluate the impact of a range of catch options $( \pm 50 \%)$ for 2013-2017. We assume

430 that the age-pattern in F's will be the same as for 2012. Normally this is based on the average $F$

431 pattern in recent years; however, in our state-space model the F's are already smoothed so this

432 does not seem necessary. For each catch option the fully selected $F$ is found by solving Equation

433 (2). We use the state-space model to project values for $M$ 's. Projected recruitment, stock weights 434 and proportions mature are assumed to be equal to the average of their 2010-2012 values. No 435 projection errors are included in these values although the recruitment values are unknown and 436 estimated by the model and this estimation uncertainty is included in the stochastic projections. 437 These are done internally when fitting the model and we compute standard errors for projection 438 results using the delta method. This allows the $M$-process errors to accumulate as the number of 439 projection years increases and this should give more realistic quantification of uncertainty about 440 these projections. This approach also incorporates uncertainty about the initial stock size and 441 catches in the projections.

\section{Results}

443 Four model formulations are presented: 
1. Base formulation. The upper bound on catch was set at 1.5 times the reported catch (i.e. the lower bound) prior to 1993 and twice the report catch during 1993-2012.

2. Scenario 2 (or S2 for short). The upper bound on catch is 1.25 times the lower bound for all years. This represents the situation where reported catch is more accurate than assumed in the base model.

3. Scenario 3 (S3). The DFO RV q is estimated separately for stock ages 2-6 and 7+. This formulation may allow for some domed age-pattern in $\mathrm{q}$.

4. Scenario 4 (S4) did not include a change in the spatial distribution of the stock and did not include the inshore data (Acoustics or Sentinel surveys).

In all scenarios there was a major conflict in the Sentinel gillnet and DFO RV surveys and tagging data. The Sentinel indices (see DFO 2013) were at about the same level in 2010-2012 as in 1997-1999 whereas the DFO RV surveys increased substantially. The model could not reconcile these differences. We decided to omit the Sentinel gillnet survey indices from the model estimation because of uncertainty about how these fixed gear catch rates relate to the stock as a whole.

The base model estimate of SSB in 2012 (Table 2) was similar to the estimate from model S2 but both were considerably lower than the S3 estimate. The 2012 SSB estimate from S4 was the highest. However, stock status in 2012 (SSB/Blim) was very similar for all models and similar to the survey model used by DFO (i.e. Cadigan 2013a) in the 2013 assessment of this stock. The DFO precautionary approach biomass limit reference point (Blim) for this stock was set as the average SSB during 1983-1989 (DFO 2011b). The status evaluation is based on beginning-ofyear SSB to conform to the usual practice of DFO. All formulations give very similar stock status results (Fig. 1 and Supplemental Figs.S1-S4). Estimates of total and fishing mortality in 
467

468

469

470

471

472

473

474

475

476

477

478

479

480

481

482

483

484

485

486

487

488

489

2012 (Table 2) have relatively high CV's but, in light of this, are similar. Average Z estimates

for the base and S2-S3 models are similar to the 0.27 value in DFO (2013). The relatively high

CV's for the mortality rate estimates may partially be related to no tagging data in the model since 2006. Estimates of the various variance parameters were all similar. The base model results differed most with the S4 model formulation (Fig. 2) compared to the other formulations (see also Supplemental Figs. S5-S7). The S4 model indicated a greater decline in SSB until 1995 and then a greater increase during 2005-2012. This model indicated much higher recruitment productivity and $M$ during $1995-2005$. The base model estimates of $M$ were particularly high at stock ages 5-7 in 1992-1994 (Fig. 3), similar to models S2 and S3 (Supplemental Figs.S8-S9), whereas the S4 model also estimated high M's at age five in 2002-2003 (Supplemental Fig.S10). All models indicated that $M$ is age dependent and can vary substantially over a few years.

The base model fit the data well (Supplemental Figs.S11-S20). There were no major patterns in residuals indicating conflicting signals in the data. Hence, there were no significant retrospective patterns either (Fig. 4). One concern is that eight of ten residuals for the last 4 cohorts in the model had positive DFO RV residuals (Supplemental Fig. S13) but did not appear as strong in the catch age compositions (Supplemental Fig. S11). This is considered further in the Discussion. The model predicted catch was close to reported catch around 1990 and 2000 (Fig. 5). There was fairly large between-year change in the ratio of reported to predicted catch which may not be reasonable. The age-patterns in F's (Fig. 6) broadly make sense, with higher selection at older ages prior to 1992 when a substantial fraction of landings were taken by otter-trawls that have a sigmoidal selection function (Myers and Hoenig 1997), whereas after 1992 most reported commercial landings are by fixed gear and predominately gillnets. Note that the selectivity changed substantially in 2003 when there was a large scale inshore fish kill due to freezing and 
490 some of the carcasses, evidently the larger ones, were collected by fishermen and sampled by

491 DFO like a regular fishery. The model indicates an increase in selectivity towards older ages

492 starting in 2009 which may not be realistic (see Discussion).

493 A large fraction of the stock was estimated to be outside of the DFO RV survey area during

494 1995-2005 (Figs. 7 and 8). This is in addition to the part of the stock that was regularly outside

495 of the survey area in the autumn.

496 We conducted 5-year projections till 2017 to evaluate the implications of future catch levels.

497 Some of the projection inputs are given in Table 3. The projections were based on a range of

498 catch multipliers, from 0.5 to 1.5 . Results indicate the stock should continue to increase (Fig. 9)

499 although even if catch were reduced by $50 \%$ there is less than $5 \%$ probability that the stock will

500 exceed Blim in 5 years; that is, the upper $95 \%$ confidence limit is $89 \%$ of Blim in 2017 . The

501 projections are highly uncertain, particularly after 2014. Projection results were reasonably

502 robust to the four model formulation we investigated (Fig.s S21-S24).

503 We assessed the impact of two alternative choices for $\sigma_{r}^{2}$ compared to the base value, $\sigma_{r}^{2}=1$.

504 We increased $\sigma_{r}$ to 2.0 and this choice had little impact on results. For example, SSB in 2012

505 decreased from $72.4 \mathrm{Kt}$ to $72.1 \mathrm{Kt}$, and SSB in 2012 relative to Blim decreased from $11.7 \%$ to

$506 \quad 11.6 \%$. We decreased $\sigma_{r}$ to 0.1 and this had a little more impact. SSB in 2012 increased to 77.1

507 Kt and SSB in 2012 relative to Blim increased to $12.3 \%$. These changes were all well within the

508 range of uncertainty for the estimates.

509 The self-test simulations for the base model did not indicate serious bias in the estimation of SSB

510 or average $F$ at ages 3-8 (Supplemental Fig. S25). The latter was not weighted by population 
511 size. The number of simulations that converged was $95 \%$. Most of the standard deviations of the

512 random effects were under-estimated (Supplemental Fig. S26), particularly for tagging $F^{\prime}$ s $\left(\sigma_{f x}\right)$.

\section{Discussion}

514 The state-space model developed here addresses difficult problems in fish stock assessment, 515 notably biased catches, uncertain $\mathrm{M}$ and changes in survey catchability. This was possible for

516 northern cod because of the rich data (tagging and surveys) available for this stock. We

517 demonstrated in a highly plausible scenario that there were large changes in the DFO RV $q$

518 during 1995-2007 and this survey on its own may not always have provided a reliable indicator

519 of trends in the stock. The catchability of this autumn survey will be sensitive to when fish, that

520 are inshore in the summer to feed, return in the autumn to over-wintering grounds. Nonetheless,

521 our inferences about stock status are broadly consistent with the survey-based model recently

522 used to assess this stock. SSB in 2012 was estimated to be $12 \%$ of Blim in our base model and

523 also in Cadigan (2013a), although in the latter model SSB was estimated to be about 1\% of Blim

524 during 1995-2005 whereas in the base model it was near 3\% on average. The main difference in

525 the two models is how much the stock has increased. The base model suggests SSB in 2012 was

5263.6 times the average during 1995-2005 whereas the model in Cadigan (2013a) suggests it was

52714 times bigger which is more similar to the S4 result of an 11.2 fold increase. The S4 model

528 assumed a year invariant q for the DFO RV survey, similar to Cadigan (2013a), so it is not

529 surprising that these models give similar SSB trend information.

530 In the base model we assumed that the RV catchability since 2009 was the same as during $1983-$

5311994 (Fig. 8) but if this is not the case then our estimates of stock size could be biased. Recent

532 tagging results that are not included in the model indicate that fishery exploitation rates were 
2\%-6\% on average for $2010-2012$ (DFO, 2013) while the base model estimates were 5\%-7\% for ages 5-12 combined. If our estimates of stock size during 2010-2012 were 50\% higher then our exploitation rates would be around $4 \%$ and more consistent with the recent tagging results. The change in fishery selectivity towards older ages since 2009 may also be a consequence of an over-estimation of $F$ at older ages, and consequently $Z$, during this period when $M$ was estimated to be close to 0.2 (Table 3), in which case the model could not account for the increase in the catch age-composition using constant selectivity. All of this suggests a possibility that our estimates of recent stock size may be biased low.

We estimated large increases in natural mortality rates, particularly at ages 5-7, during 19921994. These estimates have fairly high CV's, but others have also concluded that there is evidence that M increased for Northwest Atlantic cod stocks (e.g. Shelton et al. 2006; Swain 2011). The causes remain uncertain but predation and poor condition immediately prior to spawning have been suggested for some of these stocks. Our lack of understanding of the causes and magnitude of the spike in $M$ affects the precision of short-term forecasts because these forecasts have to include the possibility that such an event will occur again. This is an important reason why the CV's of our projections get large so quickly. It also affects the precision of our estimates of the $M$ process errors. If we knew that this spike was due to exceptional circumstances that were unlikely to occur again then it would be better to model this as a onetime change in $M$ in addition to an age and year auto-correlated stochastic process. In an unreported exploratory run we did this and the CV on the 2017 projection of SSB/Blim deceased from $70 \%$ to $50 \%$. The accuracy of the $M$ estimates can be improved by utilizing more tagging information that exists but were not available to us. The rich tagging information for this stock also can be used to estimate fishery selectivity and this is a useful area to improve the model. 
556 Most residuals for the DFO RV survey were positive for the last four cohorts in the base model

557 but negative in the commercial age compositions. It is possible that the selectivity at these young

558 ages is more complex and variable than the model suggests. Another possible improvement is to

559 model the temporal autocorrelation for ages $2-4$, which are mostly not targeted sizes, separately

560 from ages five and older. This also highlights another major source of uncertainty affecting the

561 precision of short-term forecasts and that is the precision of recent recruitment that will become

562 mature and contribute to SSB in the next few years. Better estimates of the abundance of O-

563 group and one year old cod and their mortality rates until they reach exploitable sizes will

564 improve short-term forecasts for fisheries management.

565 In our base (i.e. highly plausible) model scenario we estimated a large change in DFO RV survey

$566 q$ because of a shift in the over-wintering distribution of some cod from the offshore to the

567 inshore. The change in $q$ was derived based on acoustic biomass estimates in Smith Sound;

568 however, some of this biomass may include a portion of typical inshore over-wintering bay

569 stocks that would be accounted for by the DFO RV survey $q$ parameters. For example, since

5702009 less than 1000 tonnes of cod have over-wintered in Smith Sound (G. Rose, Marine Institute

571 of Memorial University of Newfoundland, St. John's, NL, personal communication, 2014) and

572 would be accounted for by $q$. We can only speculate on the amount of over-wintering cod in

573 Smith Sound before 1995 but Rose et al. (2011) concluded that the weight of the historical

574 evidence suggested that there was no exceptional overwintering or spawning concentration in

575 Smith Sound prior to 1995 and especially not in the early 1990s. Hence, we make no adjustments

576 to account for this.

577 We feel that including process errors in $M$ provides a potential advantage compared to the way

578 Gudmundsson and Gunnlaugsson (2012) and Nielsen and Berg (2014) included process errors in 
579 Equation (1), particularly if the process errors are viewed as deviations in $M$ from assumptions.

580 Our process errors directly and consistently affect both Equation (1) and (2), whereas their

581 process errors directly affected only Equation (1). One should be able to derive Equation (2)

582 from Equation (1) and the assumption that the fraction $F_{a, y} / Z_{a, y}$ of the deaths in a cohort in year $y$

583 (i.e. $N_{a, y}-N_{a+1, y+1}$ ) are due to fishing; however, this is not the case for their equations. Their $\mathrm{Z}_{\mathrm{a}, \mathrm{y}}$

584 may be different than $-\log \left(\mathrm{N}_{\mathrm{a}, \mathrm{y}} / \mathrm{N}_{\mathrm{a}+1, \mathrm{y}+1}\right)$. On the other hand, our model does not explicitly allow

585 for immigration whereas the models proposed by Gudmundsson and Gunnlaugsson (2012) and

586 Nielsen and Berg (2014) do. However, Equation (3) can partially account for immigration

587 although a cohort cannot increase in size as it gets older, unlike the models in Gudmundsson and

588 Gunnlaugsson (2012) and Nielsen and Berg (2014). Equation (3) may also reflect mis-reported

589 catch although we prefer to model this directly using catch bounds.

590 In a preliminary version of the northern cod model in which tagging information was not used

591 and DFO RV survey catchability was assumed to be constant for all years we found that the

592 process error variance parameter was highly confounded with the measurement error variance.

593 The total likelihood was fairly flat for different choices of these parameters. This if often the case

594 with age-aggregated production models where Bayesian approaches are commonly used and

595 informative priors for process and/or measurement error variance have to be used (e.g. Meyer

596 and Millar 1999). This problem has also been recognized in some age-disaggregated stock

597 assessment models (i.e. Linton and Bence 2008). However, this does not seem to be a problem in

598 the approaches of Gudmundsson and Gunnlaugsson (2012) and Nielsen and Berg (2014). This

599 suggests the possibility that their assumption of process errors in Equation (1) but not in

600 Equation (2) may be the reason they can separate this source of variation from measurement 
601 error. However, if the main source of process error is in M, which will affect both Equations (1)

602 and (2), then it is not clear how reliable their approaches may be. This requires further research.

603 Self-test simulations did not indicate large biases in SSB or $F$; however, many of the variance

604 parameters were slightly under-estimated, and some substantially so (i.e. $\sigma_{f x}$ and $\sigma_{D}$ ), which could

605 mean that standard errors of model estimates (e.g. stock status, projections) are too low. There is

606 a well-known bias problem with maximum likelihood estimates of variance parameters for

607 models with many mean parameters (e.g. Barndorff-Nielsen and Cox 1994). The bias is negative.

608 Our state-space model is not highly parameterized, with only 49 parameters in the base model

609 formulation and 12 of these were covariance parameters. The sample size was 1371 . However,

610 for the 37 mean parameters there were $16 \theta$ tag reporting rate parameters for the data from the 16

611 tagging experiments we used from Myers et al. (1996), and 7 qs,y parameters for the 7 years of

612 age-composition information from Smith Sound (Rose et al. 2011) that we used. Hence the

613 likelihood components for these two data sources are highly parameterized and their variance

614 parameters $\left(\sigma_{f x}\right.$ and $\left.\sigma_{D}\right)$ had the largest biases. Many adjustments have been proposed to address

615 this problem (e.g. Barndorff-Nielsen and Cox 1994). One approach that is often successful (e.g.

616 Wang et al. 2015) is restricted maximum likelihood estimation. This can be implemented by

617 simply integrating mean parameters out of the likelihood. Model estimation involves two stages,

618 one for variance parameters and one for mean parameters. This may be a useful improvement to

619 the estimation procedure for our model.

620 There are several other ways that the state-space model can be improved and we have already

621 alluded to some of these. Most importantly, offshore acoustic surveys have been conducted for

622 several years since 2005 and this information, once published, should be included in our model.

623 Additional historic and contemporary tagging information also exists that should improve the 
624 precision of $F$ and $M$ estimates. Including size and age composition information for tagged fish is

625 also useful. Commercial catch and age composition information since 1959 were used in

626 previous assessments of northern cod. It may be difficult to include this information in our state-

627 space model and at the same time estimate both $F$ and $M$; however, it can be done with

628 additional assumptions about $M$ and by including more of the historic tagging data. Including

629 more of the historic data should improve our understanding of temporal variability in stock

630 productivity which is critical information for estimating fisheries management (e.g. maximum

631 sustainable yield) reference points. Information on fleet compositions may improve modelling

632 the age-patterns in $F$.

633 Fisheries managers and stakeholders deserve to know if model-based stock assessment advice is

634 reliable and robust to model assumptions and uncertainties in data. This can be complicated to

635 demonstrate and there is a trade-off between the usefulness of a model and robustness. A model

636 that is completely insensitive to all changes in data inputs and assumptions will not be useful.

637 Further simulation testing of our proposed model using a spatio-temporal fishery simulation

638 framework and including reasonable deviations in model assumptions is required to demonstrate

639 the robustness and reliability of the approach. However, a challenge (e.g. Deroba et al. 2014) is

640 to decide what the simulation framework should be in an integrative modeling context involving

641 acoustic and trawl surveys, and tagging information.

\section{Acknowledgements}

643 The work received financial support from a Research \& Development Corporation (RDC) of

644 Newfoundland and Labrador grant and a Natural Sciences and Engineering Research Council of

645 Canada (NSERC) grant to N.C. The author thanks the stock assessment science staff of Fisheries 
646 and Oceans Canada at the Northwest Atlantic Fisheries Science Center, and scientists at the

647 Center for Fisheries Ecosystems Research of Memorial University of Newfoundland, for many

648 discussions and contributions that assisted in the development of this paper.

\section{References}

650

Aanes, S., Engen, S., Sæther, B. E., \& Aanes, R. 2007. Estimation of the parameters of fish stock dynamics from catch-at-age data and indices of abundance: can natural and fishing mortality be separated? Canadian Journal of fisheries and aquatic sciences, 64: 1130-1142.

Agresti, A. 1996. An introduction to categorical data analysis. Wiley, New York.

Aitchison, J. 2003. The Statistical Analysis of Compositional Data (reprint ed.). The Blackburn Press. Caldwell, New Jersey, USA.

Baird, J. W., Bishop, C. A., \& Murphy, E. F. 1991. Sudden changes in the perception of stock

658 size and reference catch levels for cod in northeastern Newfoundland shelves. NAFO Scientific 659 Council Studies, 16: 111-119.

660 Barndorff-Nielsen, O. E., and Cox, D. R. 1994. Inference and Asymptotics. Chapman and Hall, 661 London.

662 Berg, C.W., and Kristensen, K. 2012. Spatial age-length key modelling using continuation ratio 663 logits. Fisheries Research, 129: 119-126.

664 Bousquet, N., Cadigan, N., Duchesne, T., and Rivest, L.-P. 2010. Detecting and correcting 665 underreported catches in fish stock assessment: trial of a new method. Canadian Journal of 666 Fisheries and Aquatic Sciences, 67: 1247-1261. 
667 Brattey, J., and Cadigan, N.G. 2003. Estimation of Short-term Tagging Mortality among Adult 668 Atlantic Cod (Gadus morhua). Fisheries Research, 66: 223-233.

669 Brattey, J., Cadigan, N.G., Dwyer, K., Healey, B.P., Morgan, M.J., Murphy, E.F., Maddock

670 Parsons, D., and Power, D. 2011. Assessment of the cod (Gadus morhua) stock in NAFO

671 Divisions 2J+3KL in 2010. DFO Canadian Science Advisory Secretariat Research Document

672 2010/103. viii +108 p.

673 Brattey, J., and Healey, B. P. 2003. Exploitation rates and movements of Atlantic cod (Gadus 674 morhua) in NAFO Divs. 3KL based on tagging experiments conducted during 1997-2002. DFO

675 Canadian Science Advisory Secretariat Research Document 2003/032. iv + 24 p.

676 Brattey, J., and Healey, B. P. 2007. Exploitation and movements of Atlantic cod (Gadus morhua)

677 in NAFO Division 3KL: tagging results from the reopened fishery in 2006. DFO Canadian

678 Science Advisory Secretariat Research Document 2007/027. iv + 43 p.

679 Brinch, C.N., Eikeset, A.M., and Stenseth, N.C. 2011. Maximum likelihood estimation in 680 nonlinear structured fisheries models using survey and catch-at-age data. Canadian Journal of 681 Fisheries and Aquatic Sciences, 68: 1717-1731.

682 Cadigan, N. 2010. Trends in Northwest Atlantic Fisheries Organization (NAFO) Subdivision 683 3Ps Cod (Gadus morhua) stock size based on a separable total mortality model and the Fisheries 684 and Oceans Canada Research Vessel survey index. DFO Canadian Science Advisory Secretariat 685 Research Document 2010/015. iv +43 p.

686 Cadigan, N. G. 2011. Confidence intervals for trawlable abundance from stratified-random 687 bottom trawl surveys. Canadian Journal of Fisheries and Aquatic Sciences, 68: 781-794. 
688

689

690

691

692

693

694

695

696

697

698

699

700

701

702

703

704

705

706

707

708

Cadigan, N. 2013a. Update of SURBA+ for 2J3KL cod. DFO Canadian Science Advisory Secretariat Research Document 2013/054. v + 19 p.

Cadigan, N. 2013b. An evaluation of growth models for predicting 2J3KL cod stock weights-atage. DFO Canadian Science Advisory Secretariat Research Document 2013/053. v + 27 p.

Cadigan, N. G. and Brattey, J. 2003. Semi-parametric estimation of tag loss and reporting rates for tagging experiments using exact time-at-liberty data. Biometrics. 59: 869-876.

Cadigan, N. G. and Brattey, J. 2006. Reporting and shedding rate estimates from tag-recovery experiments on Atlantic cod (Gadus morhua) in coastal Newfoundland. Canadian Journal of Fisheries and Aquatic Sciences, 63: 1944-1958.

de Valpine, P. D., and Hilborn, R. 2005. State-space likelihoods for nonlinear fisheries timeseries. Canadian Journal of Fisheries and Aquatic Sciences, 62: 1937-1952.

Deroba, J.J., Butterworth, D.S., Methot, R.D. Jr., De Oliveira, J.A.A., Fernandez, C., Nielsen, A., Cadrin, S.X., Dickey-Collas, M., Legault, C.M., Ianelli, J., Valero, J.L., Needle, C.L., O’Malley, J.M., Chang, Y-J., Thompson, G.G., Canales, C., Swain, D.P., Miller, D.C.M., Hintzen, N.T., Bertignac, M., Ibaibarriaga, L., Silva, A., Murta, A., Kell, L.T., de Moor, C.L., Parma, A.M., Dichmont, C.M., Restrepo, V.R., Ye, Y., Jardim, E., Spencer, P.D., Hanselman, D.H., Blaylock, J., Mood, M., Hulson, P.-J. F. 2014. Simulation testing the robustness of stock assessment models to error: some results from the ICES strategic initiative on stock assessment methods. ICES Journal of Marine Science, doi:10.1093/icesjms/fst237.

DFO. 2007. 2007 Survey of the Recreational Cod Fishery of Newfoundland and Labrador. http://www.dfo-mpo.gc.ca/stats/rec/can/NLCod2007/toc-eng.htm. 
709 DFO. 2011. Stock Assessment of Northern (2J3KL) cod in 2011. DFO Canadian Science

710 Advisory Secretariat Science Advisory Report 2011/041.

711 DFO. 2013. Stock Assessment of Northern (2J3KL) Cod in 2013. DFO Canadian Science

712 Advisory Secretariat Science Advisory Report 2013/014.

713 Fournier, D.A., Skaug H.J., Ancheta J., Ianelli J., Magnusson A., Maunder M.N., Nielsen A., and

714 Sibert J. 2012. AD Model Builder: using automatic differentiation for statistical inference of

715 highly parameterized complex nonlinear models. Optimization Methods and Software, 2: 233-

716249.

717 Francis, R. I. C. 2014. Replacing the multinomial in stock assessment models: A first step.

718 Fisheries Research, 151, 70-84.

719 Gudmundsson, G. 1994. Time series analysis of catch-at-age observations. Applied Statistics 43:

$720 \quad 117-126$.

721 Gudmundsson, G., and Gunnlaugsson, T. 2012. Selection and estimation of sequential catch-at-

722 age models. Canadian Journal of Fisheries and Aquatic Sciences 69: 1760-1772.

723 Halliday, R. G., and Pinhorn, A. T. 1996. North Atlantic fishery management systems: a

724 comparison of management methods and resource trends. Journal of Northwest Atlantic Fishery

725 Science, 20: 1-143

726 Hammond, T.R., and Trenkel, V.M. 2005. Censored catch data in fisheries stock assessment.

727 ICES Journal of Marine Science, 62: 1118-1130. 
728 Hutchings J. A., and Myers R. A. 1995. The biological collapse of Atlantic cod off

729 Newfoundland and Labrador: an exploration of historical changes in exploitation, harvesting,

730 technology and management. In The North Atlantic Fisheries: Successes, Failures and

731 Challenges, pp. 38-93. Ed. by R. Arnason and L. Felt. Institute of Island Studies, Charlottetown,

732 Prince Edward Island, Canada.

733 Konrad, C., Brattey, J., and Cadigan, N.C. 2012. Reporting rates xxx. draft soon to submit.

734 Kristensen, K. 2013. TMB: General random effect model builder tool inspired by ADMB. R

735 package version 1.0. http://www.tmb-project.org. Accessed 15 April 2015.

736 Kvist, T., Gislason, H., and Thyregod, P. 2000. Using continuation-ratio logits to analyze the

737 variation of the age composition of fish catches. Journal of applied statistics, 27: 303-319.

738 Lilly, G. R. 2008. The decline, recovery, and collapse of Atlantic cod (Gadus morhua) off

739 Labrador and eastern Newfoundland. in Resiliency of gadid stocks to fishing and climate change.

740 Edited by G. Kruse, K. Drinkwater, JN Ianelli, JS Link, DL Stram, V. Wespestad, and D.

741 Woodby. Alaska Sea Grant Program, University of Alaska, Fairbanks, Alaska, 67-88.

742 Linton, B. C., and Bence, J. R. 2008. Evaluating methods for estimating process and observation

743 error variances in statistical catch-at-age analysis. Fisheries Research: 94, 26-35.

744 Martín-Fernández, J. A., Barceló-Vidal, C., and Pawlowsky-Glahn, V. 2003. Dealing with Zeros

745 and Missing Values in Compositional Data Sets Using Nonparametric Imputation. Mathematical

746 Geology: 35, 253-278.

747 Martell, S., 2011. iSCAM Users Guide Version 1.0, Available from

748 https://sites.google.com/site/iscamproject/. Accessed 21 October 2013. 
749 Martell, S., Schweigert, J., Cleary, J., Haist, V., 2011. Moving towards thesustainable fisheries

750 framework for Pacific herring: data, models, and alter-native assumptions. In: Stock Assessment

751 and Management Advice for the British Columbia Pacific Herring Stocks: 2011 Assessment and

$752 \quad 2012$ Forecasts. Canadian Science Advisory Secretariat Research Document 2011/136.

753 http://www.dfo-mpo.gc.ca/csas-sccs/index-eng.htm/. Abstract accessed 30November 2013.

754 Maunder, M. N., \& Deriso, R. B. 2011. A state-space multistage life cycle model to evaluate

755 population impacts in the presence of density dependence: illustrated with application to delta

756 smelt (Hyposmesus transpacificus). Canadian Journal of Fisheries and Aquatic Sciences, 68:

$757 \quad 1285-1306$.

758 Maunder, M. N., and Piner, K. R. 2014. Contemporary fisheries stock assessment: many issues

759 still remain. ICES Journal of Marine Science, doi:10.1093/icesjms/fsu015.

760 Millar, R. B., and Meyer, R. 2000. Bayesian state-space modeling of age-structured data: fitting

761 a model is just the beginning. Canadian Journal of Fisheries and Aquatic Sciences, 57: 43-50.

762 Meyer, R., and Millar, R. B. 1999. BUGS in Bayesian stock assessments. Canadian Journal of

763 Fisheries and Aquatic Sciences, 56: 1078-1087.

764 Morales, J. M., Haydon, D. T., Frair, J., Holsinger, K. E., \& Fryxell, J. M. 2004. Extracting more

765 out of relocation data: building movement models as mixtures of random walks. Ecology, 85:

$766 \quad 2436-2445$.

767 Myers, R. A., Barrowman, N. J., Hoenig, J. M., \& Qu, Z. 1996. The collapse of cod in Eastern

768 Canada: the evidence from tagging data. ICES Journal of Marine Science: Journal du Conseil, 769 533: 629-640. 
770 Myers, R. A., \& Hoenig, J. M. 1997. Direct estimates of gear selectivity from multiple tagging

771 experiments. Canadian Journal of Fisheries and Aquatic Sciences, 54: 1-9.

772 Nielsen, A., Berg, C. W. 2014. Estimation of time-varying selectivity in stock assessments using

773 state-space models. Fisheries Research, http://dx.doi.org/10.1016/j.fishres.2014.01.014.

774 Patterson, T. A., Thomas, L., Wilcox, C., Ovaskainen, O., \& Matthiopoulos, J. 2008. State--space

775 models of individual animal movement. Trends in ecology \& evolution, 23: 87-94.

776 R Core Team. 2014. R: A Language and Environment for Statistical Computing. R Foundation 777 for Statistical Computing, Vienna, Austria. URL http: //www.R-project.org/.

778 Rose, G. A. 2007. Cod: the Ecological History of the North Atlantic Fisheries. Breakwater 779 Books Ltd, St John’s, NF, Canada. 591 pp.

780 Rose, G. A., Nelson, R. J., and Mello, L. G. 2011. Isolation or metapopulation: whence and 781 whither the Smith Sound cod?. Canadian Journal of Fisheries and Aquatic Sciences, 68: 152-169.

782 Rindorf, A., and Lewy, P. 2001. Analyses of length and age distributions using continuation783 ratio logits. Canadian Journal of Fisheries and Aquatic Sciences, 58: 1141-1152.

784 Schnute, J. T. 1994. A general framework for developing sequential fisheries models. Canadian 785 Journal of Fisheries and Aquatic Sciences, 51: 1676-1688.

786 Schnute, J. T., and Haigh, R. 2007. Compositional analysis of catch curve data, with an 787 application to Sebastes maliger. ICES Journal of Marine Science: Journal du Conseil, 64: 218788233. 
789 Shelton, P. A., \& Lilly, G. R. 2000. Interpreting the collapse of the northern cod stock from

790 survey and catch data. Canadian Journal of Fisheries and Aquatic Sciences, 57: 2230-2239.

791 Shelton, P.A., Sinclair, A.F., Chouinard, G.A., Mohn, R., Duplisea, D.E., 2006. Fishing under

792 low productivity conditions is further delaying recovery of Northwest Atlantic cod (Gadus

793 morhua). Canadian Journal of Fisheries and Aquatic Sciences 63, 235-238.

794 Skaug H.J., and Fournier D.A. 2006. Automatic approximation of the marginal likelihood in 795 non-Gaussian hierarchical models. Computational Statistics \& Data Analysis, 51: 699-709.

796 Stewart, C., and Field, C. 2011. Managing the essential zeros in quantitative fatty acid signature 797 analysis. Journal of Agricultural, Biological, and Environmental Statistics, 16: 45-69.

798 Swain, D.P., 2011. Life-history evolution and elevated natural mortality in a population of 799 Atlantic cod (Gadus morhua). Evolutionary Applications 4, 18-29.

800 Swain, D. P. 2011. Natural mortality and projected biomass of southern Gulf of St. Lawrence 801 cod (Gadus morhua). DFO Canadian Science Advisory Secretariat Research Document 802 2011/040. iv +33 p.

803 Taggart, C. T., Penney, P., Barrowman, N., and George, C. 1995. The 1954-1993 Newfoundland 804 cod-tagging database: statistical summaries and spatial-temporal distributions. Canadian

805 Technical Report of Fisheries and Aquatic Sciences, 2042: 442 p.

806 Thorson, J. T. Standardizing compositional data for stock assessment. ICES Journal of Marine 807 Science, doi:10.1093/icesjms/fst224. 
808 Trine K., Gislason, H., and Thyregod, P. 2000 .Using continuation-ratio logits to analyze the 809 variation of the age composition of fish catches, Journal of Applied Statistics, 27: 303-319, 810 DOI:10.1080/02664760021628.

811 Vaida, F. and Blanchard, S. 2005. Conditional Akaike information for mixed-effects models.

812 Biometrika 92: 351-370.

813 Wang, S., Cadigan, N. G., and Benoît, H. P. 2015. Inference about regression parameters using 814 highly stratified survey count data with over-dispersion and repeated measurements. Submitted 815 to Journal of Applied Statistics. 


\section{Figure Captions}

818 Figure 1. Stock status relative to Blim (solid lines), and 95\% confidence intervals (dashed lines), 819 for the northern cod (Gadus morhua) base model formulation. Two y-axis scales are used and the 820 solid vertical line indicates where the change occurs.

821 Figure 2. Comparisons of the four northern cod (Gadus morhua) model formulations: base, S2

822 (better catch), S3 (dome $q$ ), and S4 (no change in inshore/offshore distribution), for (a) SSB, (b)

823 recruits per spawner, (c) $F$, and (d) $M$. Mortality rates are stock size-weighted averages for ages

824 5-12. Two y-axis scales are used in (a) and the solid vertical line indicates where the change 825 occurs.

826 Figure 3. Illustration of the base model estimates of $M$.

827 Figure 4. Base model retrospective estimates of (a) SSB, (b) log of average $F$, and (c) Average $Z$. 828 Circles indicate the most recent estimate for each retrospective year.

829 Figure 5. Base model estimated total catch numbers at ages 2-12 (black lines) and assumed catch 830 bounds (grey lines). The left-hand y-axis is in log scale. Superimposed is the reported/estimated 831 catch (circles) with y-axis scale on the right-hand side.

832 Figure 6. Illustration of the base model age pattern in $F$.

833 Figure 7. Illustration of the base model estimates of the proportion of the stock in Smith Sound, $834 D$.

835 Figure 8. Multiplicative change in catchability $(q)$ for the DFO RV survey, averaged for ages 5+. 
836 Figure 9. Five year base model projections of stock status. Dashed lines indicate 95\% confidence 837 intervals for projections based on status quo model predicted catch. Panel (a): Projections for 838 status quo catch (heavy solid line) and a 50\% increase or decrease in catch (thin solid lines).

839 Circles indicate status quo CV's. The grey horizontal dashed line indicates a CV $=30 \%$ and 840 projections with CV's $>30 \%$ should be interpreted with more caution. Panel (b): Projections of 841 SSB (heavy solid line) and the percent change in SSB from 2012 (grey line) for status quo catch.

842 The grey horizontal dashed line indicates a 50\% increase. 


\section{List of Tables}

844 Table 1. Definitions, model notation and parameters.

\begin{tabular}{|c|c|}
\hline$Z, F, M$ & Total, fishing, and natural mortality rates \\
\hline$\widetilde{Z}, \widetilde{F}, \tilde{M}$ & Stock size weighted average $Z, F$, and $M$ \\
\hline$N, N_{S}$ & Total and Smith Sound stock abundance \\
\hline$N_{+, a}$ & Total stock abundance at ages $a, a+1, \ldots, A$ \\
\hline$D$ & Proportion of stock in Smith Sound, $D=N_{S} / N$ \\
\hline$N_{x}$ & Number of tagged fish from experiment $x$ \\
\hline$Z_{x}, F_{x}$ & Total and fishing mortality rate for experiment $x$ \\
\hline$C, C_{o}, U$ & Model and observed fishery catch, and upper bound on catch \\
\hline$C_{x}, R_{x}$ & Model tag catch and reported catch from experiment $x$ \\
\hline$I$ & Survey index \\
\hline$P$ & Compositional data proportion \\
\hline$X$ & Inverse logistic transformation of $P$ \\
\hline$\theta, \Psi$ & vectors of all fixed- and random-effects parameters \\
\hline$\delta$ & Cohort model process error \\
\hline$\sigma_{\delta}^{2}$ & process error variance parameter \\
\hline$\varphi_{\delta, a g e}, \varphi_{\delta, y r}$ & age and year correlation in process errors \\
\hline$\sigma_{F}^{2}$ & $F$ variance parameter \\
\hline$\varphi_{F, a g e}, \varphi_{F, y r}$ & age and year correlation in $F \mathrm{~s}$ \\
\hline$\sigma_{D}^{2}$ & Variance parameter $D$ \\
\hline$\varphi_{D, a g e}, \varphi_{D, y r}$ & age and year correlation in $D$ \\
\hline$r_{1}, r_{2}$ & mean log-recruitment during (1) 1983-1992 and (2) 1993-2012 \\
\hline$\sigma_{r}^{2}$ & variance of log-recruitment \\
\hline$\sigma_{C}^{2}$ & catch measurement error \\
\hline$\sigma_{P}^{2}$ & catch age composition measurement error \\
\hline$\sigma_{I}^{2}$ & survey measurement error \\
\hline$\sigma_{f x}^{2}$ & variance of tagging $F$ deviation from stock $F$ \\
\hline$\Phi_{N}$ & cumulative distribution function for a standard normal random variable \\
\hline$\varphi_{N}$ & probability distribution function for a standard normal random variable \\
\hline$\pi_{b}$ & $=P_{b} /\left(P_{b}+\ldots+P_{B}\right)$ \\
\hline$\gamma_{y}$ & annual tag loss rate \\
\hline$\lambda_{o y}$ & externally estimated tag reporting rates for year $y=1996, \ldots, 2006$ \\
\hline$\lambda_{x}$ & reporting rate parameter for early tagging experiments \\
\hline$q$ & Survey index catchability parameter \\
\hline$\rho_{a}$ & Age pattern in $q, q_{a}=q_{\text {full }} \rho_{a}$ \\
\hline
\end{tabular}


847 Table 2. Estimates (est) of variance parameters (see Table 1) and some population parameters, 848 with percent coefficients of variation ( $\mathrm{CVx} 100)$, for four model formulations. nll denotes the 849 negative loglikelihood and AIC is the Akaike information criterion. Total and fishing mortality 850 rates ( $\mathrm{Z}$ and $\mathrm{F})$ are averaged for ages 5-12 and these averages are population size weighted.

\begin{tabular}{|c|c|c|c|c|c|c|c|c|}
\hline \multirow[b]{2}{*}{ Quantity } & \multicolumn{2}{|c|}{$\begin{array}{l}\text { Base; nll = 2629 } \\
\text { AIC }=5356\end{array}$} & \multicolumn{2}{|c|}{$\begin{array}{l}\mathrm{S} 2 ; \mathrm{nll}=2670 \\
\mathrm{AIC}=5438\end{array}$} & \multicolumn{2}{|c|}{$\begin{array}{l}\text { S3; nll = 2627 } \\
\text { AIC = 5361 }\end{array}$} & \multicolumn{2}{|c|}{$\begin{array}{l}\mathrm{S}^{*} ; \mathrm{nll}=2291 \\
\mathrm{AIC}=4659\end{array}$} \\
\hline & est & $\mathrm{CV}$ & est & $\mathrm{CV}$ & est & $\mathrm{CV}$ & est & $\mathrm{CV}$ \\
\hline$\sigma_{R V}$ & 0.414 & 10 & 0.429 & 9 & 0.437 & 9 & 0.529 & 7 \\
\hline$\sigma_{P}$ & 0.318 & 9 & 0.343 & 9 & 0.322 & 9 & 0.351 & 9 \\
\hline$\sigma_{\delta}$ & 0.536 & 16 & 0.547 & 16 & 0.540 & 16 & 0.424 & 18 \\
\hline$\sigma_{F}$ & 0.585 & 6 & 0.612 & 6 & 0.583 & 6 & 0.578 & 6 \\
\hline$\sigma_{f x}$ & 0.991 & 7 & 1.008 & 6 & 0.974 & 6 & 0.925 & 6 \\
\hline$\sigma_{D}$ & 0.502 & 32 & 0.493 & 33 & 0.484 & 35 & - & - \\
\hline$\varphi_{\delta, \text { age }}$ & 0.776 & 10 & 0.755 & 11 & 0.775 & 10 & 0.836 & 8 \\
\hline$\varphi_{\delta, y r}$ & 0.704 & 15 & 0.707 & 14 & 0.688 & 15 & 0.888 & 6 \\
\hline$\varphi_{D, y r}$ & 0.925 & 5 & 0.928 & 5 & 0.929 & 5 & - & - \\
\hline$\varphi_{D, \text { age }}$ & 0.915 & 6 & 0.918 & 6 & 0.918 & 6 & - & - \\
\hline$\varphi_{F, \text { age }}$ & 0.800 & 7 & 0.822 & 6 & 0.807 & 7 & 0.784 & 8 \\
\hline $\operatorname{Blim}(\mathrm{Kt})$ & 621 & 9 & 589 & 9 & 669 & 10 & 825 & 9 \\
\hline $\mathrm{SSB}_{2012}(\mathrm{Kt})$ & 72 & 16 & 68 & 16 & 82 & 18 & 106 & 17 \\
\hline $\mathrm{SSB}_{2012} /$ Blim & 0.117 & 13 & 0.116 & 14 & 0.122 & 14 & 0.128 & 16 \\
\hline$q_{\text {full }}$ & 1.288 & 10 & 1.361 & 10 & 1.087 & 14 & 0.892 & 9 \\
\hline $\bar{Z}_{2012}$ & 0.308 & 47 & 0.308 & 49 & 0.282 & 48 & 0.358 & 49 \\
\hline $\bar{F}_{2012}$ & 0.061 & 27 & 0.041 & 21 & 0.058 & 25 & 0.044 & 22 \\
\hline
\end{tabular}


851 Base: upper bound on total catch is $\mathbf{2} \times$ reported catch for 1993-2012, and 1.5 5 for 1983-1992.

$852 \mathrm{~S} 2$ : upper bound on total catch is $\mathbf{1 . 2 5} \times$ reported catch for all years.

853 S3: Base + survey catchabilities ( $q$ 's) estimated separately for ages 2-6 and 7+.

$854 \mathrm{~S} 4^{*}:$ Base + no change in spatial distribution. A reduced data set.

855

856

857 
858 Table 3. Projection inputs. Weight indicates both stock and catch weights (Kg). Maturity

859 indicates the proportion mature. $M$ is natural mortality and $F$ is fishing mortality in 2012 . Sel

860 denotes selectivity which is the age pattern in average $F$; that is, $F / \max _{a}\left(F_{a}\right)$.

\begin{tabular}{cccccccccc}
\hline age & weight & maturity & $F$ & Sel & $\mathrm{M}_{2013}$ & $\mathrm{M}_{2014}$ & $\mathrm{M}_{2015}$ & $\mathrm{M}_{2016}$ & $\mathrm{M}_{2017}$ \\
\hline 2 & 0.10 & 0.00 & 0.001 & 0.005 & 0.302 & 0.350 & 0.389 & 0.419 & 0.442 \\
3 & 0.28 & 0.00 & 0.004 & 0.033 & 0.196 & 0.222 & 0.243 & 0.259 & 0.270 \\
4 & 0.60 & 0.05 & 0.007 & 0.060 & 0.178 & 0.184 & 0.189 & 0.192 & 0.194 \\
5 & 1.03 & 0.35 & 0.020 & 0.165 & 0.245 & 0.231 & 0.221 & 0.215 & 0.210 \\
6 & 1.57 & 0.79 & 0.058 & 0.464 & 0.252 & 0.235 & 0.224 & 0.217 & 0.212 \\
7 & 2.29 & 0.97 & 0.095 & 0.767 & 0.229 & 0.220 & 0.214 & 0.210 & 0.207 \\
8 & 3.16 & 1.00 & 0.121 & 0.977 & 0.187 & 0.191 & 0.194 & 0.195 & 0.197 \\
9 & 4.14 & 1.00 & 0.124 & 1.000 & 0.187 & 0.191 & 0.194 & 0.195 & 0.197 \\
10 & 5.14 & 1.00 & 0.112 & 0.905 & 0.187 & 0.191 & 0.194 & 0.195 & 0.197 \\
11 & 6.31 & 1.00 & 0.076 & 0.612 & 0.187 & 0.191 & 0.194 & 0.195 & 0.197 \\
\hline
\end{tabular}




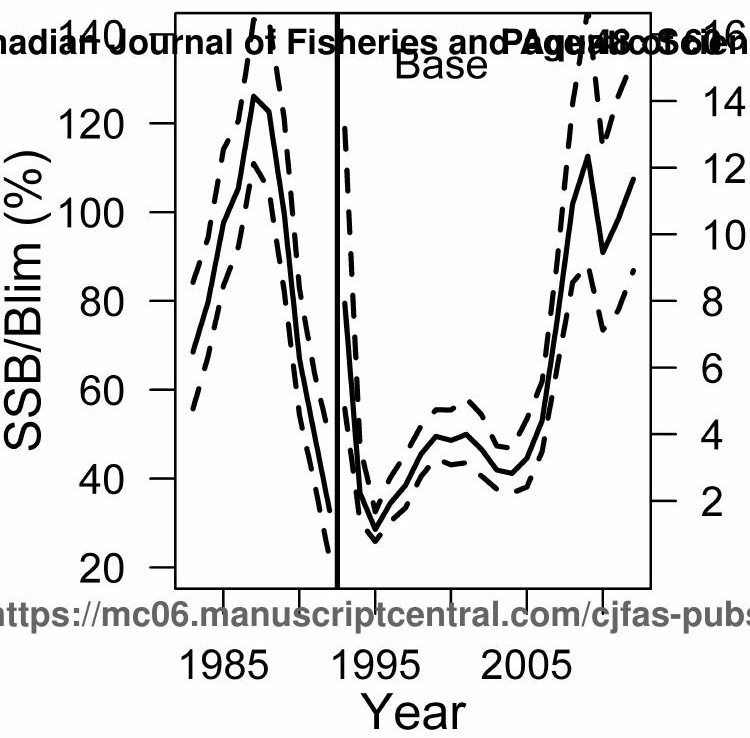


Canadian-Journal of Fisheribs-and Aquatieasrigioco 6.605

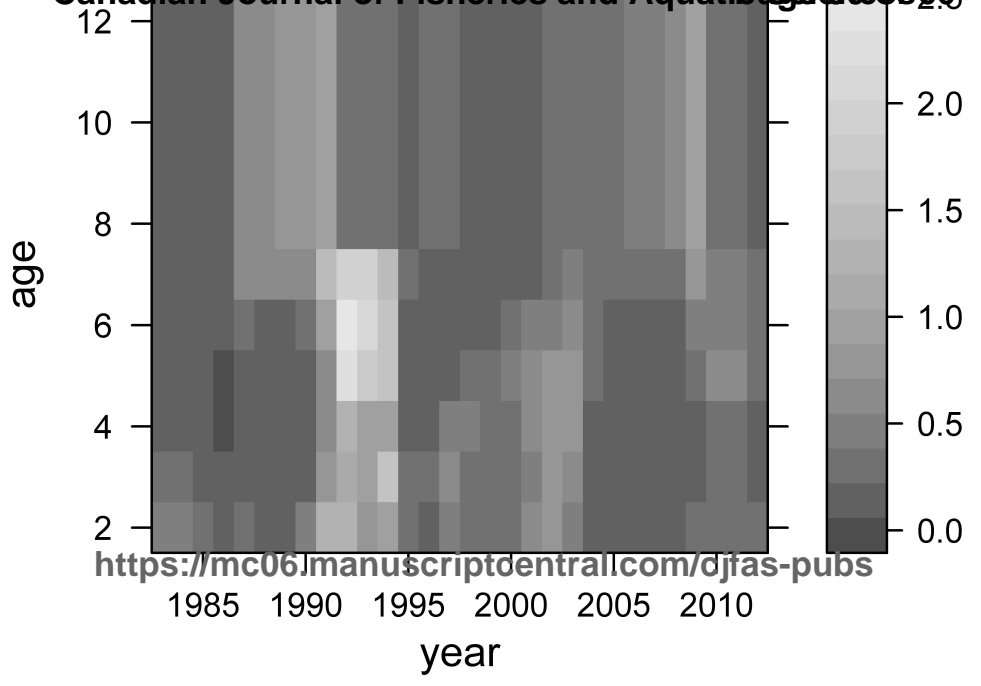


Pagariedidifournal of Fisheries-and-Aqualic Sciences

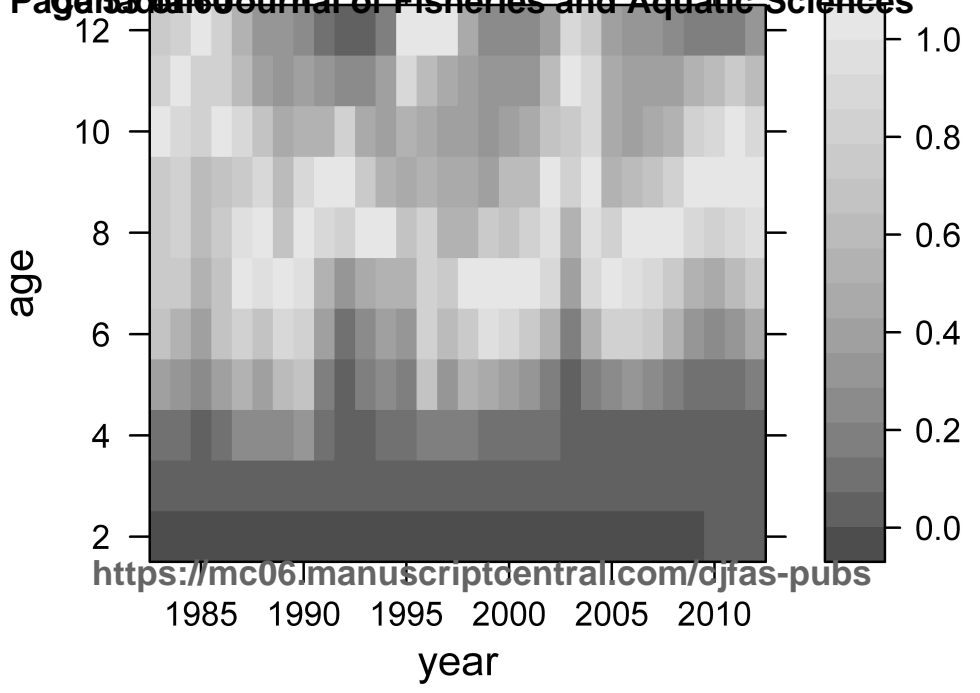


Canadian-Journal of Fisheries-ahd-Aquatiezigciesase 560

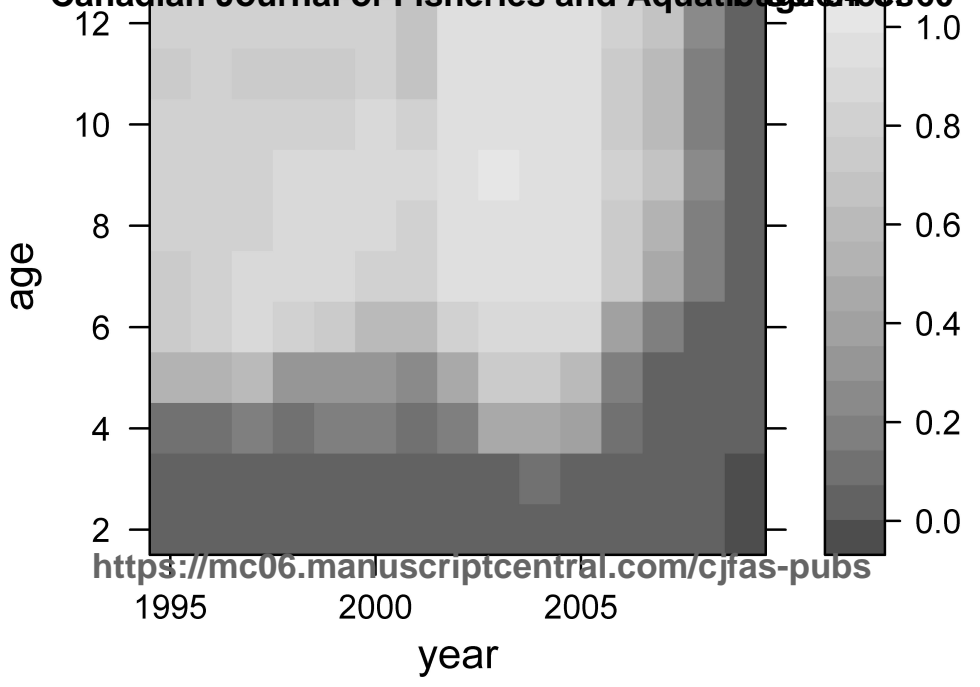




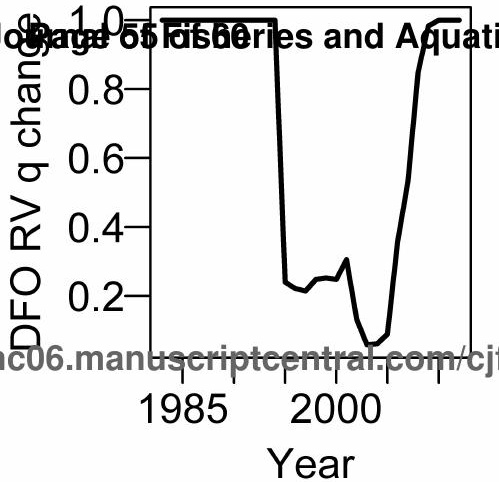




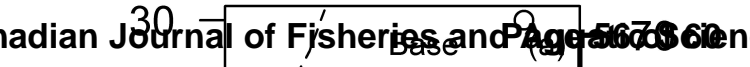
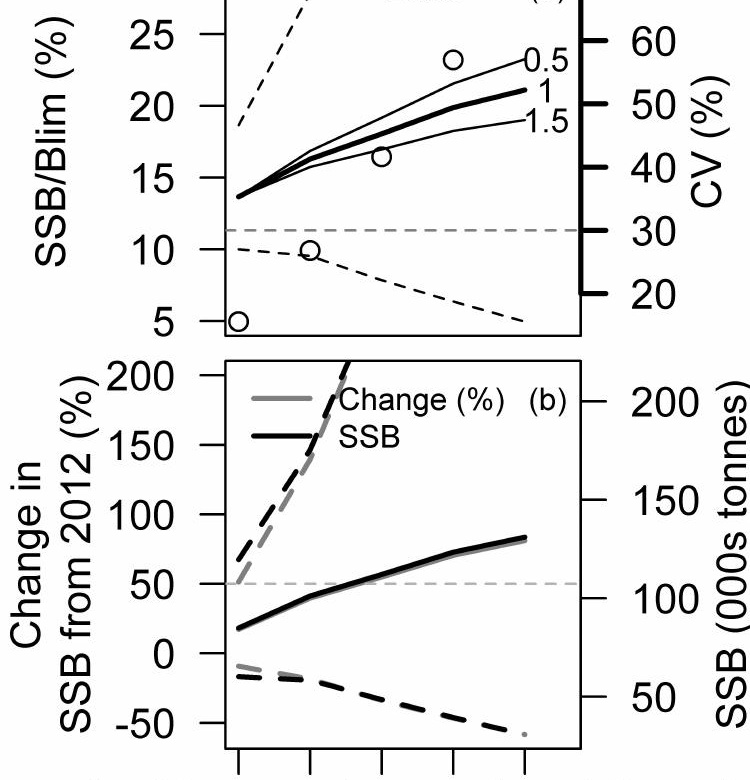

ttps://mc06.manuscriptcentral.com/cjfas-pub Year 


\section{Appendix}

\section{Vector AR(1) log-likelihood}

3 Let $\underline{z}_{t}$ be an $A x 1$ process error vector that is generated from a vector $\mathrm{AR}(1)$ process, $\underline{z}_{t}=\varphi_{\mathrm{yr}} \underline{z}_{t-1}+$

$4 \varepsilon_{t}$ where $\varepsilon_{t}$ is multivariate normal with mean $\underline{\theta}$ and covariance $\Sigma$, and $\varphi_{y r}$ is a scalar

5 autocorrelation parameter that is common to all elements of $\underline{z}$. We assume that $E\left(\underline{z}_{l}\right)=\underline{0}$ and that

$6 \varepsilon_{t}$ and $\varepsilon_{t-i}$ are independent for all $i>0$. It can be shown that the mean of the stationary

7 distribution of $\underline{z}$ is $\underline{0}$ and the covariance is $\operatorname{Var}(\underline{z})=\lim _{t \rightarrow \infty} \operatorname{Var}\left(\underline{z}_{t}\right)=\Sigma /\left(1-\varphi_{y r}^{2}\right)$. The

8 loglikelihood for $\Sigma$ and $\varphi_{y r}$ given a set of process errors $\left(\underline{z}_{1}, \ldots, \underline{z}_{n}\right)$ can be written

$$
l\left(\Sigma, \varphi_{y r} ; \underline{z}_{1}, \ldots, \underline{z}_{n}\right)=l\left(\Sigma, \varphi_{y r} ; \underline{z}_{1}\right)+\sum_{t=2}^{n} l\left(\Sigma, \varphi_{y r} ; \underline{z}_{t} \mid \underline{z}_{t-1}\right),
$$

9 where $l\left(\sum, \varphi_{y r} ; \underline{z}_{l}\right)$ is the loglikelihood based on a multivariate normal (MVN) distribution with

10 mean $\underline{\theta}$ and covariance $\Sigma /\left(1-\varphi_{y r}^{2}\right)$, and $l\left(\Sigma, \varphi_{y r} ; \underline{z}_{t} \mid \underline{z}_{t-1}\right)$ is based on the MVN distribution with

11 mean $\varphi_{y r} \underline{z}_{t-1}$ and covariance $\Sigma$, for $t=2, \ldots, n$.

12 We also assume that $\Sigma$ has a stationary AR(1) structure with diagonal elements all equal to

$13 \sigma^{2} /\left(1-\varphi_{a g e}^{2}\right)$ and off diagonal elements proportional to $\varphi_{a g e}^{|i-j|}$. Hence, the process errors are

14 auto-correlated across ages and years. The loglikelihood for $\theta=\left\{\sigma^{2}, \varphi_{y r}, \varphi_{\text {age }}\right\}$ can be further

15 simplified. First,

$$
l\left(\theta ; \underline{z}_{1}\right)=l\left(\theta ; z_{1,1}\right)+\sum_{a=2}^{A} l\left(\theta ; z_{a, 1} \mid z_{a-1,1}\right),
$$


16 where $l\left(\theta ; z_{1,1}\right)$ is the loglikelihood based on the univariate $N\left(0, \frac{\sigma^{2}}{\left(1-\varphi_{y r}^{2}\right)\left(1-\varphi_{a g e}^{2}\right)}\right)$ distribution,

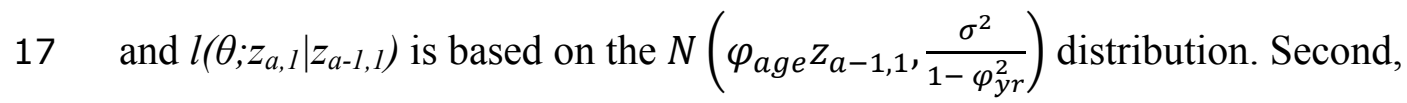

$$
l\left(\theta ; \underline{z}_{t} \mid \underline{z}_{t-1}\right)=l\left(\theta ; z_{1, t} \mid \underline{z}_{t-1}\right)+\sum_{a=2}^{A} l\left(\theta ; z_{a, t} \mid z_{a-1,1}, \underline{z}_{t-1}\right)
$$

18 where $l\left(\theta ; z_{1, t} \mid \underline{z}_{t-1}\right)$ is based on the $N\left(\varphi_{y r} z_{1, t-1}, \frac{\sigma^{2}}{1-\varphi_{a g e}^{2}}\right)$ and $l\left(\theta ; z_{a, t} \mid z_{a-1, t, \underline{z} t-1}\right)$ is based on the

$19 N\left\{\varphi_{y r} z_{a, t-1}+\varphi_{a g e}\left(z_{a-1, t}-\varphi_{y r} z_{a-1, t-1}\right), \sigma^{2}\right\}$.

\section{Continuation-ratio logit}

21 Consider the compositional data $P_{1}, \ldots, P_{B}$ for states $1, \ldots, B$ with the basic property that $P_{1}+\ldots+$

$22 P_{B}=1$. Let $X_{b}=\log \left\{P_{b} /\left(1-\sum_{i=1}^{B-1} P_{i}\right)\right\}, b=1, \ldots, B-1$. The logistic normal multinomial

23 distribution is based on assuming $X_{1}, \ldots, X_{B-1}$ has a multivariate normal distribution with some

24 correlation structure. Francis (2014) concluded that the logistic normal multinomial distribution

25 showed great promise for modelling length and age compositional data in stock assessment. The

26 distribution of $P_{1}, \ldots, P_{B}$ is generated from the logistic transformation

$$
P_{b}=\left\{\begin{array}{cc}
\frac{\exp \left(X_{b}\right)}{1+\sum_{i=1}^{B-1} \exp \left(X_{i}\right)}, & b=1, \ldots, B-1 . \\
\frac{1}{1+\sum_{i=1}^{B-1} \exp \left(X_{i}\right)}, & b=B .
\end{array}\right.
$$

27 To be more precise, Aitchison (2003) referred to Equation (A.1) as the additive logistic

28 transformation. He argued that for ordered compositional data, such as for ages and lengths, the 29 multiplicative logistic transformation is more appropriate, 


$$
P_{b}=\left\{\begin{array}{lc}
\frac{\exp \left(X_{b}\right)}{\prod_{i=1}^{b}\left\{1+\exp \left(X_{i}\right)\right\}}, & b=1, \ldots, B-1 . \\
\frac{1}{\prod_{i=1}^{B-1}\left\{1+\exp \left(X_{i}\right)\right\}}, & b=B .
\end{array}\right.
$$

30 The inverse of this transformation is

$$
X_{b}=\log \left(\frac{P_{b}}{1-P_{1}-, \ldots,-P_{b}}\right)=\log \left(\frac{P_{b}}{P_{b+1}+\ldots,+P_{B}}\right), b=1, \ldots, B-1
$$

31 This was the approach used by Stewart and Field (2011) in diet composition analyses of seabirds

32 and seals. If we define $\pi_{b}=P_{b} /\left(P_{b}+\ldots+P_{B}\right)=\operatorname{Prob}($ State $=b \mid$ State $\geq b)$ then

$$
X_{b}=\log \left(\frac{\pi_{b}}{1-\pi_{b}}\right), b=1, \ldots, B-1
$$

33 Equation A.4 is also the continuation-ratio logit as defined by Agresti (1996) and has been used

34 for modelling length and age distributions by Kvist et al. (2000), Rindorf and Lewy ( 2001),

35 Berg and Kristensen (2012), and possibly others.

36 This compositional data theory has been developed for strictly positive compositions in which all

$37 P_{b}>0$. In practice there may be zeros that can be real (i.e. essential) or due to rounding. Issues

38 related to zeros are discussed by Martín-Fernández et al. (2003) and Stewart and Field (2011).

39 For age and length composition data it may be difficult to decide whether zeros are essential or

40 rounded. Cohort abundance never goes extinct in our state-space model so we consider zeros to

41 be due to rounding. We used a simple replacement strategy in which zeros were replaced with a

42 value of 0.5 and then the catches were rescaled so that the total annual catch with replacement

43 values for zeros is the same as the original total catch.

\section{Tag loss rates}


45 Cadigan and Brattey $(2003,2006)$ estimated tag loss rates from information on double tagged

46 fish. They showed that Kirkwoods tag loss model provided a good fit to the data. Let $\Gamma\left(y-y_{x}\right)$

47 denote the cumulative probability that a tag is retained on a fish in year $y$ when it was initially

48 tagged in year $y_{x}$. Kirkwoods model is $\log \{\Gamma(t)\}=\beta_{1} \log \left\{\beta_{1} /\left(\beta_{1}+\beta_{2} t\right)\right\}$, with mean tag loss

49 rate

$$
\gamma(t)=\Gamma^{-1}(t) \frac{d}{d t}\{1-\Gamma(t)\}=-\frac{d}{d t} \log \{\Gamma(t)\}=\frac{\beta_{1} \beta_{2}}{\beta_{1}+\beta_{2} t}
$$

50 This is a decreasing function from $\beta_{2}$ when $t=0$ to zero as $t \rightarrow \infty$, and the rate of decrease

51 depends on $\beta_{2} / \beta_{1}$. The $\gamma_{t}$ in Equations (18) and (20) are evaluated at mid-year using Equation

52 (A.5) and including the fraction of year at liberty in the release year. We use the same parameter 53 values as in Brattey and Healey (2007). 